\title{
LTSER platforms as a place-based transdisciplinary research infrastructure: learning landscape approach through evaluation
}

\author{
Per Angelstam (i) - Michael Manton - Marine Elbakidze • Frans Sijtsma • \\ Mihai Cristian Adamescu • Noa Avni · Pedro Beja • Peter Bezak • \\ Iryna Zyablikova $\cdot$ Fatima Cruz • Vincent Bretagnolle $\cdot$ Ricardo Díaz-Delgado • \\ Bruno Ens • Mariia Fedoriak • Giovanna Flaim • Simone Gingrich • \\ Miri Lavi-Neeman · Sergey Medinets • Viesturs Melecis · Jose Muñoz-Rojas • \\ Jessica Schäckermann • Andrea Stocker-Kiss • Heikki Setälä • Natalie Stryamets • \\ Maija Taka $\cdot$ Gaelle Tallec $\cdot$ Ulrike Tappeiner $\cdot$ Johan Törnblom • \\ Taras Yamelynets
}

Received: 13 April 2018/Accepted: 27 October 2018/Published online: 26 November 2018

(C) The Author(s) 2018

\begin{abstract}
Context Place-based transdisciplinary research involves multiple academic disciplines and non-academic actors. Long-Term Socio-Ecological Research (LTSER) platform is one concept with $\sim 80$ initiatives globally.
\end{abstract}

P. Angelstam $(\bowtie) \cdot$ M. Elbakidze · J. Törnblom

School for Forest Management, Faculty of Forest Sciences, Swedish University of Agricultural Sciences (SLU), PO Box 43, 73921 Skinnskatteberg, Sweden e-mail: per.angelstam@slu.se

\section{Elbakidze}

e-mail: marine.elbakidze@slu.se

J. Törnblom

e-mail: johan.tornblom@slu.se

\section{Manton}

Faculty of Forest Science and Ecology, Institute of Forest Biology and Silviculture, Aleksandras Stulginskis University, Studentu g. 13, Akademija, 53362 Kaunas, Lithuania

e-mail: michael.manton@asu.lt

\section{F. Sijtsma}

Faculty of Spatial Sciences, University of Groningen, PO Box 800, 9700 AV Groningen, The Netherlands e-mail: f.j.sijtsma@rug.nl
Objectives As an exercise in learning through evaluation we audited (1) the siting, construction and maintenance of individual LTSER platforms, and (2) them as a distributed infrastructure for place-based transdisciplinary research with focus on the European continent.

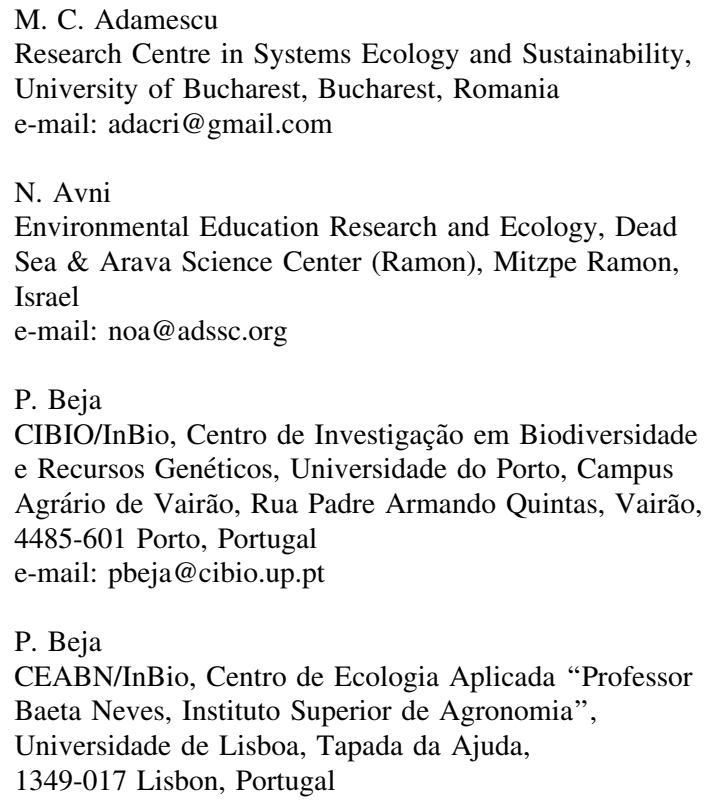


Methods First, we defined a normative model for ideal performance at both platform and network levels. Second, four surveys were sent out to the 67 selfreported LTSER platforms officially listed at the end of 2016. Third, with a focus on the network level, we analyzed the spatial distribution of both long-term ecological monitoring sites within LTSER platforms, and LTSER platforms across the European continent. Fourth, narrative biographies of 18 platforms in different stages of development were analyzed.

Results While the siting of LTSER platforms represented biogeographical regions well, variations in land use history and democratic governance were not well represented. Platform construction was based on 2.1 ecological monitoring sites, with $72 \%$ ecosystem and $28 \%$ social system research. Maintenance of a platform required three to five staff members, focused mostly on ecosystem research, was based mainly on national funding, and had 1-2 years of future funding secured. Networking with other landscape approach concepts was common.

Conclusions Individually, and as a network, LTSER platforms have good potential for transdisciplinary knowledge production and learning about sustainability challenges. To improve the range of variation of Pan-European social-ecological systems we

\section{P. Bezak}

Institute of Landscape Ecology, Slovak Academy of

Sciences, Akademická 2, 94901 Nitra, Slovakia

e-mail: peter.bezak@savba.sk

\section{Zyablikova · T. Yamelynets}

Faculty of Geography, Ivan Franko National University,

Doroshenko street 41, L'viv 79000, Ukraine

e-mail: ibulavenko@gmail.com

T. Yamelynets

e-mail: taras.yamelynets@gmail.com

F. Cruz

Sustainable Forest Management Research Institute, University of Vallodolid, Campus de la Yutera, Av. de Madrid 44, 34.071, Palencia, Spain

e-mail: fatimaregina.cruz@uva.es

V. Bretagnolle

LTSER Zone Atelier Plaine \& Val de Sevre, CEBC-

CNRS, 79360 Villiers en Bois, France

e-mail: vincent.bretagnolle@cebc.cnrs.fr encourage interfacing with other landscape approach concepts.

Keywords Europe $\cdot$ Landscape approach · Learning through evaluation - Social-ecological system .

Stakeholder engagement - Transdisciplinary research

\section{Introduction}

Natural capital is an essential foundation for human well-being (De Groot et al. 2010). The ecosystem services framework was developed with the aim to improve inclusion of natural capital into political and economic decision making across governance levels (Millennium Ecosystem Assessment 2005). However, fragmented policy, governance and land ownership are obstacles for multifunctional land management and spatial planning (e.g., Muñoz-Rojas et al. 2015; Bezák et al. 2017; Garrido et al. 2017; Naumov et al. 2018). To complement the ecosystem services approach as an advocacy tool in land use policy, governance and planning, implementation on the ground requires skills to navigate the complexity of interactions within landscapes as social-ecological systems. Furthermore, to support translation of policy and plans into action, it is essential to focus both on

\section{R. Díaz-Delgado}

Estación Biológica de Doñana-CSIC, Avda. Américo

Vespucio 26, 41092 Seville, Spain

e-mail:rdiaz@ebd.csic.es

B. Ens

SOVON Dutch Centre for Field Ornithology,

Postbus 6521, 6503 GA Nijmegen, The Netherlands

e-mail: bruno.ens@sovon.nl

M. Fedoriak

Department of Ecology and Biomonitoring, Chernivtsi

National University, 2 Kotsyubynski street,

Chernivtsi 58029, Ukraine

e-mail: m.m.fedoriak@gmail.com

G. Flaim

Research and Innovation Centre, Fondazione Edmund Mach, Via Mach 2, 38010 S. Michele all'Adige, TN, Italy

e-mail: giovanna.flaim@fmach.it 
sustainable development as an inclusive societal process (Baker 2006), and on ensuring sustainability in social-ecological systems (Norton 2005). Landscape is a well-established concept that can aid knowledge production and learning by fostering transdisciplinarity, thus integrating researchers and other knowledge producers representing different disciplines, as well as stakeholders representing different sectors at multiple levels (Termorshuizen and Opdam 2009).

The Council of Europe (2000) defines landscapes as spaces of social and ecological integration: "an area, as perceived by people, whose character is the result of the action and interaction of natural and/or human factors". The term landscape captures the manifold dimensions of places where people live and work (Matthews and Selman 2006; Pedroli et al. 2006). Simultaneous consideration of landscapes' biophysical, anthropogenic and intangible interpretations at multiple scales (e.g., Grodzynsky 2005; Angelstam et al. 2013a, b) represents a holistic approach to securing provision of ecosystem services. This requires maintaining functional ecological, or green, infrastructure through spatial planning (Angelstam et al. 2017a, 2018a), and landscape stewardship towards integrated land use management (Bieling and Plieninger 2017). Climate, geomorphology, soils

\footnotetext{
S. Gingrich

Institute of Social Ecology Vienna, University of Natural Resources and Life Sciences, Schottenfeldgasse 29, 1070 Vienna, Austria

e-mail: Simone.Gingrich@aau.at
}

\author{
M. Lavi-Neeman \\ The Arava Institute for Environmental Studies, Kibbutz \\ Ketura, 88840 D.N. Hevel Eilot, Israel \\ e-mail:mirilav@gmail.com

\section{S. Medinets} \\ Regional Centre for Integrated Environmental \\ Monitoring, Odessa National I. I. Mechnikov University, \\ 7 Mayakovskogo lane, Odessa 65082, Ukraine \\ e-mail: s.medinets@gmail.com \\ V. Melecis \\ Institute of Biology, University of Latvia, Miera iela 3, \\ Salaspils, Riga 2169, Latvia \\ e-mail: viesturs.melecis@lu.lv
}

and the flow of water determine the particular natural ecosystems, and form the biophysical checkerboard underpinning natural capital. However, human land use has severely modified once naturally dynamic ecosystems with low human impact, which resulted in traditional cultural, agricultural, forestry and built-up landscapes. Additionally, different land cover types provide intangible cultural values, including sense of place to people (Elbakidze et al. 2017). When landscapes have been intensively transformed to deliver only one kind of ecosystem service, trade-offs with other services may not be satisfied, and disservices may occur (Potschin and Haines-Young 2013; Deng et al. 2016; Locatelli et al. 2017).

To maintain natural capital in terms of biodiversity (Noss 1990) through functional green (ecological) infrastructure (e.g., European Commission 2013), thereby enhancing human well-being, modified landscapes often require capacity-building in social systems, and action through conservation, management and restoration in ecological systems. To scale up research and development in support of sustained delivery of ecosystem services is a challenging task (Angelstam et al. 2017a). This type of scaling up in landscapes as social-ecological systems (Matthews and Selman 2006) require identification of the acceptable level of modification of the biophysical

\author{
J. Muñoz-Rojas \\ ICAAM - Instituto de Ciências Agrárias e Ambientais \\ Mediterrânicas, Universidade de Évora, Núcleo da Mitra \\ Gab. 206, Edificio dos Regentes Agrícolas, Apartado 94, \\ 7006-554 Évora, Portugal \\ e-mail: jmrojas@uevora.pt
}

\section{J. Schäckermann}

Dead Sea and Arava Science Center, 8882000 DN Chevel Eilot, Israel e-mail: jessica@adssc.org
A. Stocker-Kiss
Environment Agency Austria, Spittelauer Lände 5, 1090 Vienna, Austria
e-mail: Andrea.Stocker-Kiss@umweltbundesamt.at
H. Setälä
Faculty of Biological and Environmental Sciences, University of Helsinki, Lahti, Finland e-mail: Heikki.Setala@helsinki.fi 
environment (e.g., Manton and Angelstam 2018), place-based coordination of human management of land and water resources, as well as engaging and incentivizing stakeholders and actors to act sustainably (e.g., Dawson et al. 2017). The general term landscape approach captures this complex web of interactions (Axelsson et al. 2011; Sayer et al. 2013, 2015; Sabogal et al. 2015).

To enhance regionally adapted implementation of policies aimed at sustainable development and sustainability in local social-ecological systems, a wide range of landscape approach concepts aimed towards place-based knowledge production and engaged stakeholder collaboration have emerged (Axelsson et al. 2011, 2013). One such concept is the Long-Term Socio-Ecological Research (LTSER) platform (e.g., Haberl et al. 2006; Mirtl et al. 2008, 2013; Anon 2009; Grove et al. 2013; Singh et al. 2013; Gingrich et al. 2016; Bretagnolle et al. 2018). Currently there are 80 LTSER platform initiatives globally (Mirtl et al. 2018). The LTSER network emerged as a bottom up process, where existing local and national initiatives became part of a network and recognized at the European level (Singh et al. 2013). Conditions for joining the LTSER network (usually) include: support by the platform's local, regional and national authorities, the existence of long-term datasets (especially biodiversity indicators but also abiotic variables) and the inclusion and integration of socio-economic data (Haberl et al. 2006, 2009; Mirtl et al. 2013). Dick et al.

\author{
N. Stryamets \\ Nature reserve "Roztochya", Sitchovuh Strilciv 7, \\ Ivano-Frankove 81070, Ukraine \\ e-mail: natastr@gmail.com \\ M. Taka \\ Dept. of Built Environment, Aalto University, Espoo, \\ Finland \\ e-mail: maija.taka@aalto.fi \\ G. Tallec \\ UR HYCAR, Irstea, 1 rue Pierre Gilles de Gennes, \\ 92160 Antony, France \\ e-mail: gaelle.tallec@irstea.fr \\ U. Tappeiner \\ Eurac research, 39100 Bolzano, BZ, Italy \\ e-mail: Ulrike.Tappeiner@uibk.ac.at \\ U. Tappeiner \\ Department of Ecology, University of Innsbruck, \\ Sternwartestr. 15, 6020 Innsbruck, Austria
}

(2018) showed that this vision has become reality in terms of a rapid increase of research publications. Enhancing collaboration among LTSER platforms at the international level is the next desirable level of ambition towards using multiple landscapes as a laboratory (Angelstam et al. 2013a; Holzer et al. 2018).

However, while landscape approach concepts, such as LTSER platform, are commonly advocated, and implementation of initiatives are highlighted as success stories, formal audits against a norm that states what should be delivered are rarely made (Sayer et al. 2015). Hence, it is difficult to assess what efforts to implement landscape approach concepts on the ground actually deliver. Evaluation as a professional activity plays an important part towards improving the understanding about "what really works". The learning through evaluation concept captures this challenge (Lähteenmäki-Smith 2007; Luederitz et al. 2017; Van Cuong et al. 2017).

The aim of this study is to assess how European LTSER platform initiatives live up to the LTSER platform concept's own norms developed for placebased knowledge production and learning towards sustainable landscapes (Mirtl et al. 2013; Singh et al. 2013). To achieve this, we combine a comparative and a longitudinal approach to evaluate LTSER platforms as a research infrastructure aimed at supporting the implementation of contemporary policies about biodiversity conservation and provisioning of ecosystem services as a foundation for human well-being. First, to define a normative model for the ideal performance of LTSER at platform and network levels, we used both published articles and steering documents on the LTSER platform concept. Second, we analyzed the spatial distribution both of constituent long-term ecological monitoring sites located inside LTSER platform areas, and of platforms across European gradients of biophysical, anthropogenic and intangible interpretations of landscape. Third, we created four surveys with increasing complexity that were sent out to the 67 self-reported LTSER platforms officially listed at end of 2016. Fourth, we compiled narrative biographies for 18 LTSER platforms in different development stages and used them as qualitative case studies to complement the quantitative analysis. The discussion focuses on how landscape approach concepts such as LTSER can be sustained both as local hubs of problem-solving landscape laboratories, and 
how they can form a research infrastructure and collaborate with each other, as well as with other similar initiatives.

\section{Methods and materials}

\section{Normative model}

To assess performance of individual LTSER platforms we developed a normative model by integrating Grove's et al. (2013) architectural metaphor "sitingconstruction-maintenance" and Mirtl's et al. (2013) triangle of region and actors (i.e. landscape as a coupled social-ecological system), research, infrastructure and co-ordination (Fig. 1) (see also Anon 2009), and the need for networking among platforms that represent social-ecological gradients in Europe (e.g., Mirtl et al. 2008; Metzger et al. 2010). This approach resulted in four criteria and generation of 16 indicators for which verifier variable data were collected (Table 1) (for the terms criterion, indicator and verifier variable, see Lammerts van Bueren and Blom 1997).

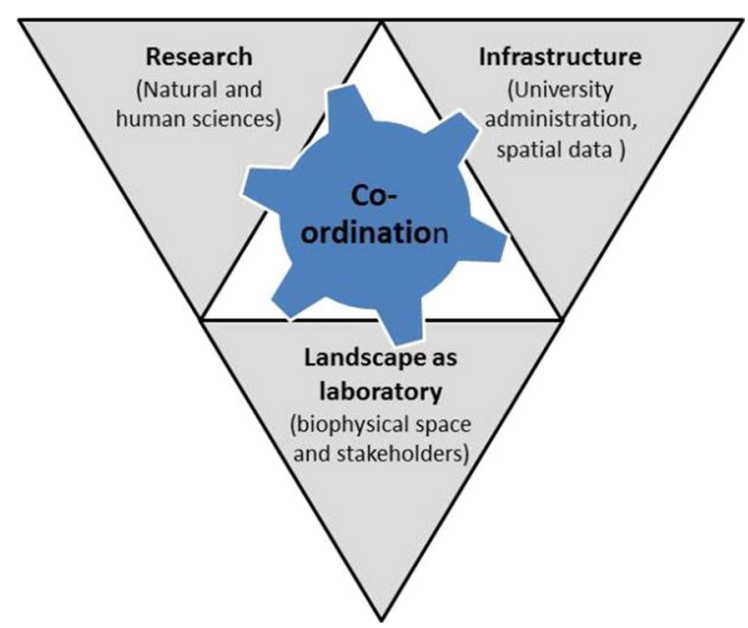

Fig. 1 Landscape approach according to the architectural metaphor of the LTSER platform concept (Grove et al. 2013; Mirtl et al. 2013) involves (A) siting a landscape as a socioecological system laboratory and engaging stakeholders in knowledge production and learning, (B) constructing by integrating researchers from different disciplines and securing an infrastructure for collecting and analyzing quantitative and qualitative data, and (C) maintaining continuous facilitation and co-ordination to sustain transdisciplinarity(see Table 1)
Analyses of the DEIMS-SDR data base

\section{Number of LTSER platforms and their spatial distribution}

At the core of our effort towards learning through evaluation is the Dynamic Ecological Information Management System-Site and Dataset Registry (DEIMS-SDR) database (https://data.lter-europe.net/ deims/). The aim of DEIMS-SDR is to be the most comprehensive catalogue of global environmental research facilities, featuring foremost but not exclusively information about all Long-Term Ecosystem Research (LTER) sites (Mollenhauer et al. 2018), and to provide data accessibility to researchers, policymakers, land managers and the general public. Thus, it is crucial to analyze both (1) LTSER platform data and (2) the LTER sites contained within each LTSER platform using the DEIMS-SDR system (see Fig. 2). We used this database to define the initial population of LTSER platforms to be analyzed. To create a complete list of all LTSER platforms, we downloaded all the data for all European countries and Israel. Due to uncertainties in the design and terminology (see metadata https://data.lter-europe.net/deims/ documentation/site) used within the DEIMS-SDR system, we consulted the managers of the system. For the audit process we compiled a complete database of the 67 LTSER platforms listed as of December 2016, and gradually populated it with verifier variable data for the 16 indicators (Table 1). Platforms managed by European countries but not located in Europe were removed from the analysis (e.g., LTSER Zone Atelier Hwange, Zimbabwe). Using this list, we first interrogated the DEIMS-SDR data base to create e-mailing lists for contacts with and surveys of the 67 LTSER platforms, extract data about the spatial location of the platforms and other information including the accreditation status of the platforms (formally approved or not by national organizations). We also included the LTSER platforms that were listed for 2010 as accredited European platforms (Mirtl et al. 2013, p. 434).

Because only 43 out of the 67 LTSER platforms listed in DEIMS-SDR had designated spatial data in terms of a GIS polygon, to be able to visualize their locations, we created a standardized platform area of $10,000 \mathrm{~km}^{2}$. This estimate was based on three approaches. First, this is platform size indicated in 
Table 1 Normative model with criteria, indicators, verifier variable data sources and reference to the results section for the assessment of LTSER platforms as (1) a research infrastructure based on Grove's et al. (2013) architectural metaphor "siting- construction-maintenance" (A, B, C) for individual platforms, and (2) Mirtl et al. (2013) for LTSER platforms as a distributed network (D) of LTSER platforms as part of a place-based research infrastructure

\begin{tabular}{|c|c|c|c|}
\hline Criterion & Indicators & Source for verifier variable & Data \\
\hline \multirow[t]{3}{*}{ Siting $^{\mathrm{a}}$ (A) } & 1. Ecoregional representation & Ecoregions & Figure $4 \mathrm{a}$ \\
\hline & 2. Representation of anthropogenic change & Forest change & Figure $4 b$ \\
\hline & 3. Representation of intangible interpretations & Democracy index & Figure $4 c$ \\
\hline \multirow[t]{4}{*}{ Construction (B) } & 4. Human versus natural science research & Survey-2; S4 & Figure $5 b$ \\
\hline & 5. LTER sites in LTSER platforms & DEIMS-SDR and GIS & Table 3 \\
\hline & 6. Stakeholder structure (at least five partners ${ }^{\mathrm{b}}$ ) & Survey-4: part 3 & Table 4 \\
\hline & 7. Land ownership structure & Survey-4: part 3 & Table 4 \\
\hline \multirow[t]{5}{*}{ Maintenance (C) } & 8. Number of full time workers & Survey-2: Q5 & Figure $5 \mathrm{a}$ \\
\hline & 9. How funding is spent on main functions & Survey-2: Q8 & Figure $5 b$ \\
\hline & 10. Funding sources & Survey-2: Q9 & Figure $5 c$ \\
\hline & 11. Duration of secured future funding & Survey-2: Q10 & Figure $5 d$ \\
\hline & 12. Past survival & Mirtl et al. (2013, p. 434) & Figure 6 \\
\hline \multirow[t]{4}{*}{ Network (D) } & 13. Reaction frequency & Surveys-1-4 & Table 5 \\
\hline & 14. Response time 10 days $^{\mathrm{b}}$ & Surveys-1-4 & Figure 7 \\
\hline & 15. Opportunity for socio-ecological analyses & Socio-ecological data & Figures 8 and 9 \\
\hline & 16. National support & ESFRI application & \\
\hline
\end{tabular}

${ }^{\mathrm{a}}$ Following the three clusters of landscape interpretations (Grodzynsky 2005)

${ }^{b}$ Mirtl et al. (2008)

the LTSER guidelines (100-10,000 km²; Mirtl et al. 2008). Second, from an ecological point of view we relied on the focal species approach (Lambeck 1997) to define a relevant size for LTSER platform areas. With specialized and area-demanding bird species as an example of frequently used focal species to assess habitat network functionality, a spatial planning unit should be in the order of 1000-10,000 km² (Angelstam et al. 2004, p. 435). Third, from a social system perspective the daily home-range of people across space and time can be estimated based on the observation that across time and space people do not commute more than $1.5 \mathrm{~h}$ per day, i.e. corresponding to ca. 50-60 km one-way travel distance by car or train (e.g., Lindelöw 2018). With a radius of $56 \mathrm{~km}$ around a regional center a social system landscape also covers ca. $10,000 \mathrm{~km}^{2}$.

\section{LTER sites nested within LTSER platforms?}

To analyze the number of LTER sites contained within the LTSER platforms (see Fig. 2) we downloaded the
LTER site information from the DEIMS-SDR system. To verify our results, we asked the database manager to provide information on the LTER sites within continental Europe. We were provided with a web link (https://stopopol.github.io/ef_viewer/) that opens an online mapping tool that accesses all accredited LTER Europe sites on DEIMS-SDR, and provides visualization and an export tool. The "LTER Europe sites" were all sites that belong to the regional group of "Europe", and which have been accredited by the respective national network manager. However, we could not align our result from the DEIMS-SDR system and the online tool which extracted the data from same DEIMS-SDR system. We thus assumed the data provided by the data manager from the online mapping tool was the correct selection. The online mapping tool provided fewer LTER sites than our own DEIMS-SDR data search. We attribute this to the accreditation status "approved" being based only on using the online mapping tool. Therefore, we also added the non-accredited LTER sites from DEIMS-SDR. Thus, the LTER site selection contained approved sites from 

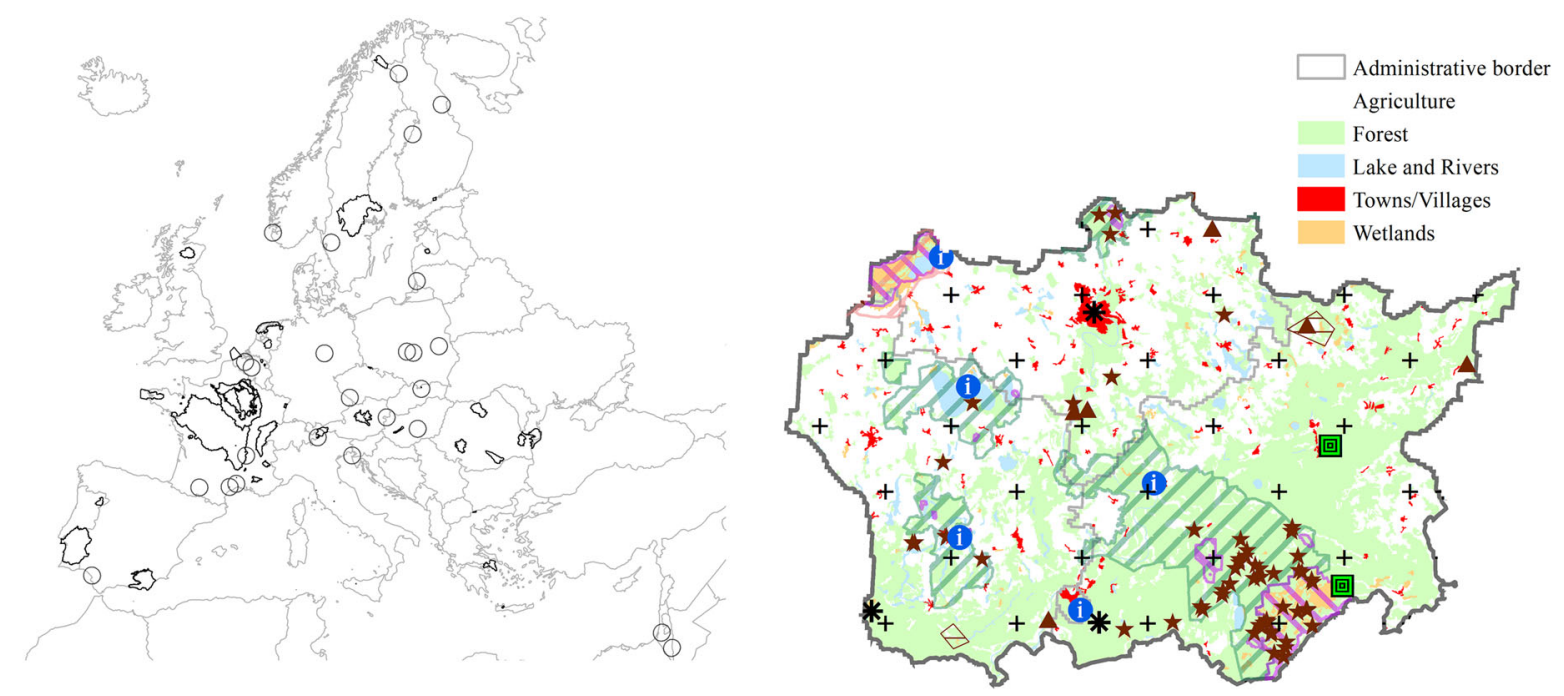

\section{Landscape level}
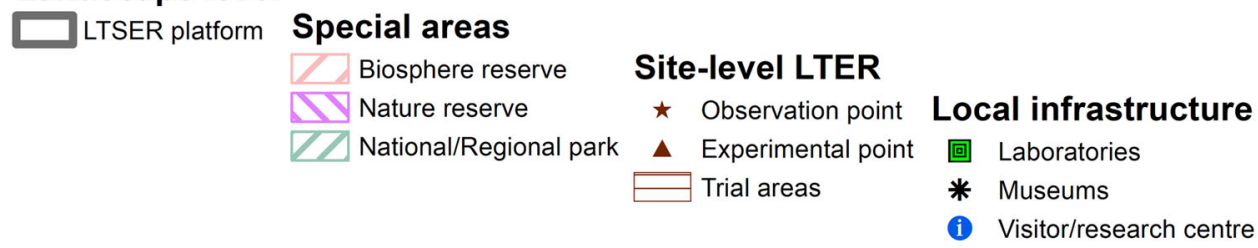

Grid points

+ Monitoring plots
Fig. 2 Illustration of 67 LTSER platforms as a multi-level place-based research infrastructure in Europe. This is illustrated by 43 LTSER platforms with a GIS-polygon in the DEIMS-SDR data base, and the remaining 24 marked as circles (left). LTSER platforms provide opportunity to address larger spatial extents and social system research topics (Metzger et al. 2010), as well as how ecological and social systems interact (Singh et al. 2013). Nested within LTSER platforms (from left to right) there are

both the online mapping tool and non-accredited sites from a direct DEIMS-SDR database download (both downloaded 2017-01-03). The LTER site data was then spatially analyzed using GIS to see which sites were located within the LTSER platforms. We identified the total number of sites, the mean number of sites per platform, how many platforms were without sites, the number of sites located in multiple platforms and platforms containing only formal sites using both the standardized platform areas $(n=67)$ and the boundaries available in the DEIMS-SDR system ( $\mathrm{n}=$ 43). special areas such as Biosphere Reserve and National Park, LTER sites that focus on ecosystem monitoring comprising highly instrumented Master Sites, Regular Sites and Satellite Sites, as well as local infrastructure and monitoring grid points (e.g., Mirtl et al. 2013, p. 417). Globally, this research infrastructure comprises $\sim 80$ long-term socio-ecological research (LTSER) platforms and $\sim 700$ long-term ecological research (LTER) sites (Mirtl et al. 2018)

Surveys sent out to LTSER platform contact persons

To collect verifier variable data that matched the 16 indicators in Table 1 we also distributed four surveys, increasing in length and effort demanded, to valid e-mail addresses of contact persons for the 67 LTSER platforms as of December 2016, and updated if needed. The first very brief survey (Survey-1) aimed at identifying the individuals responsible for LTSER platform co-ordination, ecological system research and social system research in each platform. The second survey (Survey-2) focused on characterizing the construction and maintenance of an LTSER platform. The third survey (Survey-3) was designed as an on-line web tool which LTSER platforms could use to check that their GIS polygon was correct, and if 
needed draw or adjust its shape directly. The fourth survey (Survey-4) focused on evaluating the extent to which and how LTSER platforms work with green infrastructure as a key transdisciplinary topic to address the supply and provision of ecosystem services in the LTSER platform areas as socialecological systems.

Case studies in different development stages

As a complement to the 16 indicators based on analyses of the DEIMS-SDR data base, spatial analyses, and 4 surveys, we also collected case study narratives for 18 LTSER platforms (Table 2). Case study research is a strategy that focuses on understanding the dynamics present within a specific context (Eisenhardt 1989). It aims to understand the dynamics within both singular and multiple geographical settings and across a multiplicity of disciplinary approaches and methods (Eisenhardt 1989; Stake 2006; Flyvbjerg 2011; Angelstam et al. 2013a, b).
Specifically, the case study concept provides reliability, validity and can help researchers understand tangible and intangible circumstances (Flyvbjerg 2006), and can be used to develop theories, test hypotheses, conduct audits and provide descriptions of different settings. Having emerged as bottom-up initiatives in different settings, today's LTSER platforms represent a wide gradient from those just interested in embarking on the LTSER concept, and to those that have been active for $>15$ years. The case study narratives were structured by the four assessment criteria (1) siting, (2) construction and (3) maintenance of individual platforms on one hand, and cross-platform (4) networking on the other (Table 1). Consistent with inductive research and grounded theory (Charmaz 2014), from these structured narratives we extracted and summarized the key themes for each criterion.

Table 2 List of 18 existing and potential LTSER platforms in different stages of development for which biographic narratives were collected and analyzed with respect to the 4 LTSER platform criteria siting, construction, maintenance and networking (see Table 1)

\begin{tabular}{|c|c|c|c|c|c|}
\hline $\begin{array}{l}\text { LTSER platform (code according to the } \\
\text { DEIMS-SDR data base https://data.Iter- } \\
\text { europe.net/deims/site/) }\end{array}$ & Country & $\begin{array}{l}\text { First appearance of } \\
\text { monitoring/research } \\
\text { initiative (years) }\end{array}$ & $\begin{array}{l}\text { LTSER } \\
\text { platform } \\
\text { (years) }\end{array}$ & $\begin{array}{l}\text { Area } \\
\left(\mathrm{km}^{2}\right)\end{array}$ & $\begin{array}{l}\text { Number of local } \\
\text { administrative } \\
\text { units }\end{array}$ \\
\hline Waddensee (1ter_eu_nl_001) & Netherlands & 1872 & 2016 & 6155 & 17 \\
\hline Engure (1ter_eu_lv_01) & Latvia & 1951 & 2010 & 644 & 5 \\
\hline $\begin{array}{l}\text { Oracle/BVRE Orgeval (Seine River Basin), } \\
\text { (rbv_fr_05; part of lter_eu_fr_002) }\end{array}$ & France & 1962 & 1989 & $\begin{array}{l}1200 / \\
78,000\end{array}$ & $16 / 8400$ \\
\hline Negev Highlands (1ter_eu_il_017) & Israel & 1964 & 2014 & 1700 & 2 \\
\hline Roztochya (1ter_eu_ua_004) & Ukraine & 1968 & Potential & 280 & 10 \\
\hline Tovel Lake (lter_eu_it_090) & Italy & 1976 & Potential & 90 & 1 \\
\hline Doñana LTSER Platform (lter_eu_es_001) & Spain & 1992 & 2008 & 2736 & 12 \\
\hline Plaine and Val de Sevre (1ter_eu_fr_009) & France & 1994 & 2000 & 435 & 24 \\
\hline Poloniny National Park (lter_eu_sk_010) & Slovakia & 1994 & 2017 & 342 & 10 \\
\hline Braila Island (lter_eu_ro_006) & Romania & 1995 & 2001 & 2597 & 25 \\
\hline Bergslagen (lter_eu_se_001) & Sweden & 2004 & 2011 & 44,000 & 40 \\
\hline Eizenwurzen (lter_eu_at_001) & Austria & 2004 & 2004 & 5904 & 91 \\
\hline Lithuanian coastal site (1ter_eu_lt_004) & Lithuania & 2004 & Planned & NA & NA \\
\hline Helsinki (lter_eu_fi_002) & Finland & 2006 & 2006 & 745 & 3 \\
\hline Arava (1ter_eu_il_016) & Israel & 2009 & 2009 & 1650 & 1 \\
\hline Baixo Sabor (1ter_eu_pt_002) & Portugal & 2009 & 2009 & 1590 & 5 \\
\hline Montado-Alentejo (1ter_eu_pt_001) & Portugal & 2011 & 2011 & 32,700 & 53 \\
\hline Chernivtsi region & Ukraine & 2015 & Potential & 8097 & 11 \\
\hline
\end{tabular}




\section{Results}

Siting

\section{Indicators}

The 67 LTSER platform initiatives listed in DEIMSSDR represented 23 countries, each hosting 1-17 platforms (Fig. 3). The 43 platforms with designated boundaries (i.e. GIS polygons) represented 17 countries (Fig. 3). In terms of biophysical interpretation of landscape there was good coverage of LTSER platforms in the Alpine, Boreal, Atlantic, Continental and Mediterranean biogeographic regions (Indicator A1, Fig. 4a). Gradients of anthropogenic land cover change are an important feature allowing design of comparative studies of the effects of anthropogenic factors, such as across LTSER platform areas. Forest is the most widespread potential natural land cover in Europe and ranges from lost to present but modified and intact forest landscapes. The location of LTSER platforms only in the western half of the European continent means that intact forest landscapes that can be used as reference landscapes (e.g., Potapov et al. 2008) are by and large missing (Indicator A2; Fig. 4b). Similarly, an example of an intangible interpretation of the landscape concept, countries with the full range of democratic governance values were not represented, thus missing important constituent social system variables (Indicator A3; Fig. 4c).
Narratives

Concerning siting the 18 case qualitative studies of LTSER platform initiatives illustrate the European diversity of local and regional social-ecological contexts. We identified three groups of landscape types covered by LTSER platforms. The first reflected the range of rural agricultural landscapes, from ancient cultural landscapes in abandonment with severe rural development challenges such as depopulation, and to active use of arable land and intensification of agricultural practices and landscape homogenization. The second involved river catchments and coastal areas, both of which forming gradients from urban settings including urbanization and industrial decline via agricultural areas in different socio-ecological transition, and to protected areas of different kinds. The third group was formed by historic informal regions in steep socio-ecological gradients with complex governance legacies linked to different land ownerships and landscape histories within countries, as well as locations in cross-border regions representing different systems of societal steering.

Construction

\section{Indicators}

According to Survey-1 the three functions LTSER platform co-ordination, responsibility for ecological and social science research, respectively, was served by one person [39\% of the platforms $(n=28)]$, two persons (50\% of the platforms) and three persons $(11 \%$ of the platforms). Figure $5 \mathrm{~b}$ suggests that research on
Fig. 3 Distribution among countries of 67 self-reported LTSER platforms in DEIMS-SDR at the end of 2016 and those 43 reporting digitally the boundaries of their platform. Twelve of the reported platforms in France constitute the national network of Zone Atelier LTSER (Bretagnolle et al. 2018)

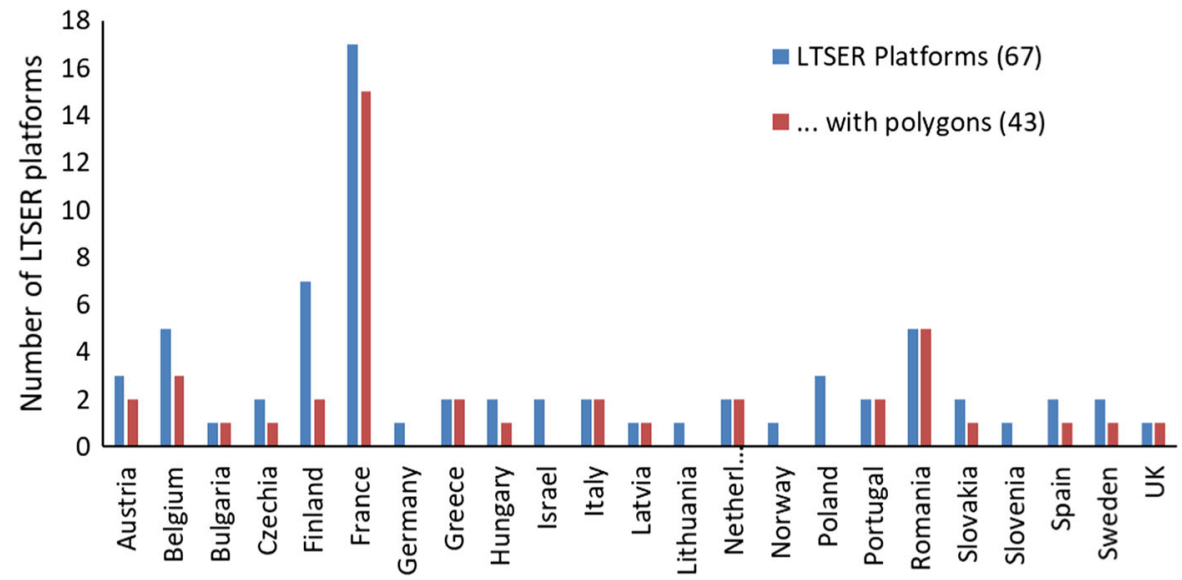


A

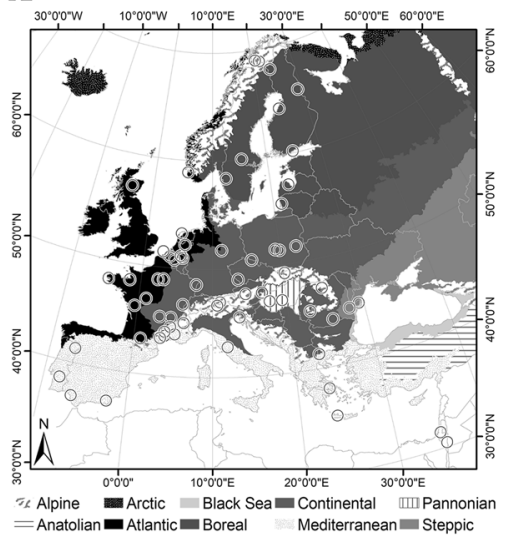

B

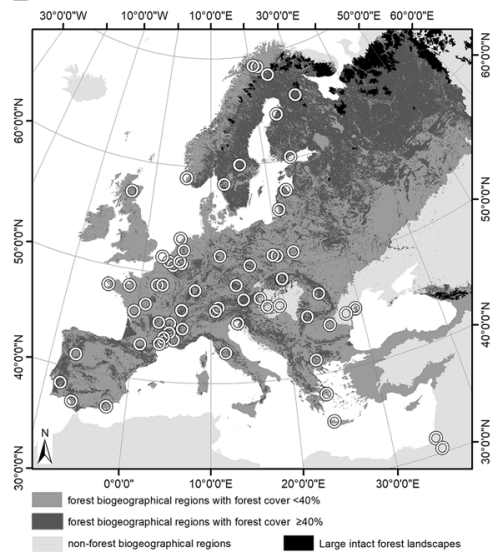

C

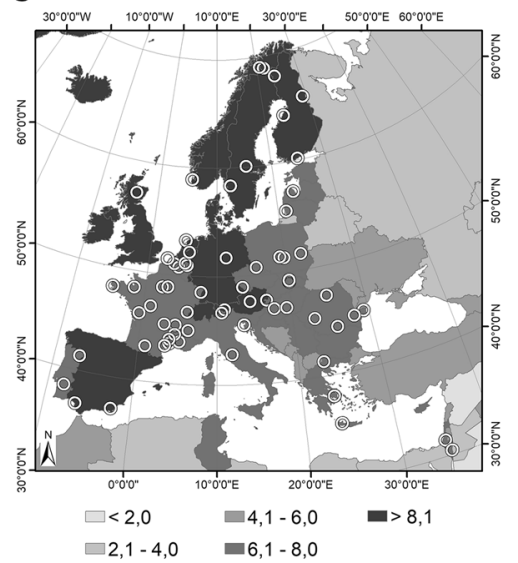

Fig. 4 Maps showing the location of 67 self-reported LTSER platforms on the European continent in relation to examples of biophysical, anthropogenic and intangible interpretations of the landscape concept (Grodzynsky 2005; Angelstam et al. 2013a). a Biogeographical regions (official delineations used in the EU Habitat Directive (92/43/EEC) and for the EMERALD Network under the Bern Convention); see http://www.eea.europa.eu/ data-and-maps/figures/biogeographical-regions-europe-2001/ biogeo_graphic.eps). b Areas with different anthropogenic impact on European forests exemplified by the gradient from

ecological systems (73\%) outnumbered research on social systems $(27 \%)$.

Regarding the indicator "constituent LTER sites in LTSER platforms" (B5, Table 3) a total of 199 LTER sites were found in the 67 platforms, and 91 in the 43 platforms that provided GIS polygons. All LTSER platforms had at least one LTER site. On average the 67 platforms with standardized $10,000 \mathrm{~km}^{2}$ areas had 2.9 sites and platforms with polygons 2.1 sites. The number of sites within approved platforms (2.3 vs. 1.7) was higher than for non-approved platforms (0.6. vs. 0.3 , see Table 3).

Concerning the profile of stakeholder participation in spatial planning for biodiversity conservation and human well-being (indicator B6) and land ownership (indicator B7) there was a clear focus on the local and regional levels (Table 4).

\section{Narratives}

The construction of LTSER platforms followed several types of trajectories, including the following three groups along a gradient from top-down to bottom-up approaches. The first came out of national level competitive initiatives to develop LTSER platforms forest biogeographical regions with forest cover $<40$ and $\geq$ $40 \%$ (Schuck et al. 2002) to large intact forest landscapes (Potapov et al. 2008). The biogeographical regions where forest is not the potential natural vegetation include arctic, Pannonian, Anatolian and Steppe; see map a. c The Economist Intelligence Unit's (2017) democracy index, which ranges from 0 to 10 . Because polygons were available for only 43 of all 67 reported LTSER platforms at the end of 2016 the map illustrates their location with a ring covering $10,000 \mathrm{~km}^{2}$

with the aim to enable integrative research about ecosystem services together with stakeholders. The second group was formed by national parks, municipalities and regional planning units that realized the need for integrated land planning to cope with socioeconomic pressures on landscapes as social-ecological systems, and biodiversity conservation through promotion of sustainable landscape development and integrated planning. This group was based on existing longterm biophysical or ecological monitoring or research as a foundation for landscape level socio-ecological system research where stakeholders identify themselves with the place. The third group was LTSER platforms the establishment of which was triggered by concrete drivers for knowledge production and learning bottomup, such as declining human population in rural areas, need for landscape restoration, a severe flooding event, securing water quality, river damming for hydroelectric use, decline of charismatic focal farmland birds and threats to beekeeping. These initiatives led to monitoring projects later evolving into research projects at local, regional and international levels, which over time did or may transform into transdisciplinary research gathering ecologists, economists and social scientists as well as stakeholders. 

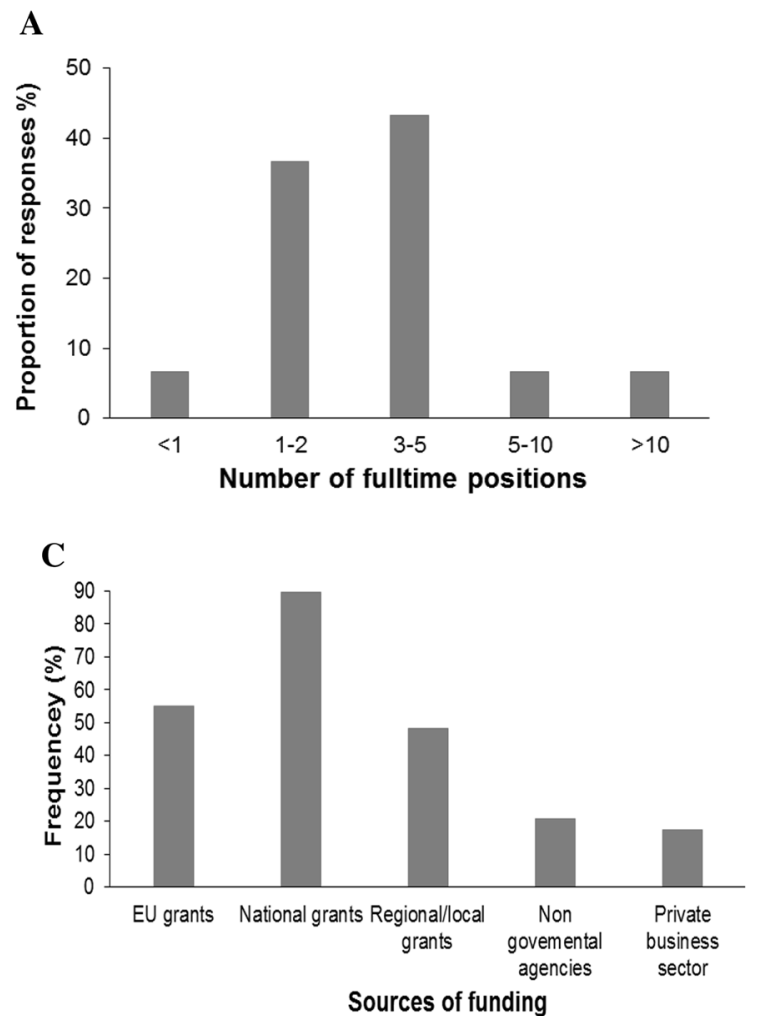

Fig. 5 a Number of full time working positions (40 h/week/ year-round) reported as a minimum to maintain a LTSER platform's basic functions in terms of co-ordination, stakeholder engagement, infrastructure and ecosystem and social system research (S2: Q5). b. LTSER platforms' estimation of how
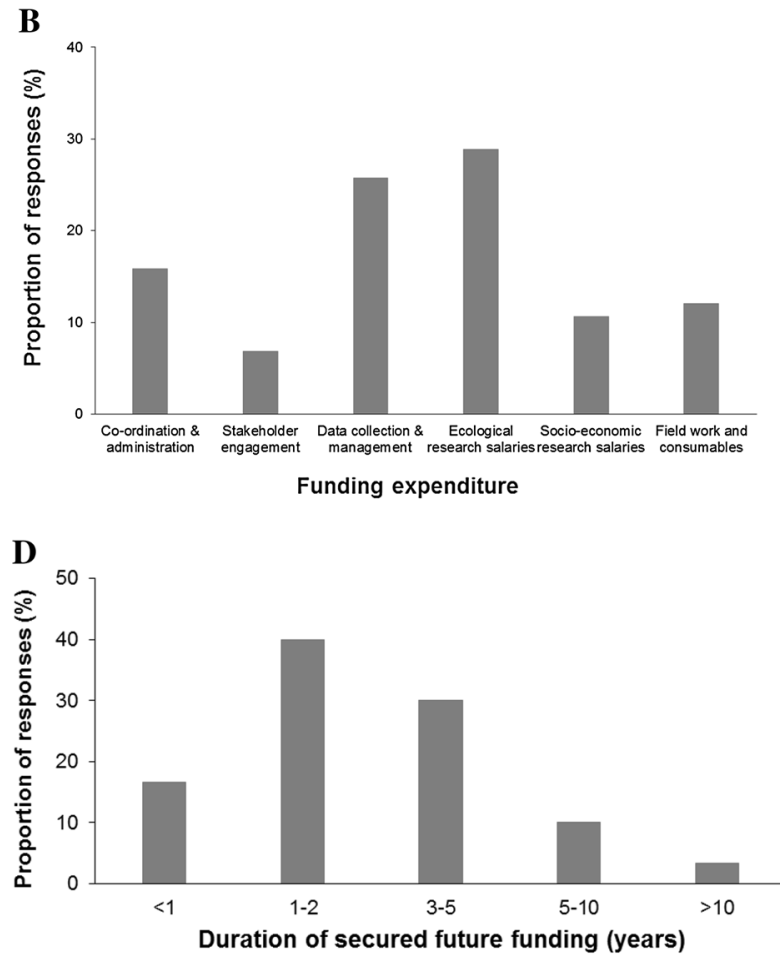

funding is spent for maintenance of these basic functions (S2: Q8). c. Current sources of funding for LTSER platforms (S2: Q9). d. LTSER platforms' estimate of how many years into the future they have secured funding to main the basic functions (S2: Q10)

Table 3 The number of LTER sites located within LTSER platforms based on external and internal queries of the DEIMS-SDR data base

LTSER platforms with $\quad$ LTSER platforms which provided own standardized $10,000 \mathrm{~km}^{2}$ areas $(\mathrm{n}$ polygons in DEIMS-SDR $(\mathrm{n}=43)$ $=67)$

Total LTER sites within LTSER platforms $n=668$, of $199(158 / 41)$ which 511 were approved and 157 were not

Mean number of sites per LTSER platform (approved $2.9(2.3 / 0.6)$ and not approved merged)

Platforms without sites (no bracket) and with site/s in 0 (67) brackets

Number of sites located within multiple platforms (approved/not approved)

Platforms with multiple sites (formal sites only)
$28(23 / 5)$

$45(34)$
$91(75 / 16)$

$2.1(1.7 / 0.3)$

An LTER site is a category of the research infrastructure distributed in situ component (comprising highly instrumented Master Sites, Regular Sites and Satellite Sites), which is nested within LTSER platforms as a category of a research infrastructure distributed in situ component dedicated to Long-Term Socio-Ecological Research on human-environment interactions at the regional/landscape scale (see Fig. 2) 
Table 4 LTSER platforms' reported profiles of stakeholder participation (percent of total) in spatial planning for biodiversity and human well-being $(\mathrm{n}=144)$, and land ownership

\begin{tabular}{llcrrr}
\hline & Level of governance & Private sector & Civil sector & Public sector \\
\hline Stakeholder participation in spatial planning & International level & 0 & 2 & 3 \\
& National level & 6 & 8 & 12 \\
& Regional level & 10 & 8 & 13 \\
Land ownership & Local level & 11 & 1 & 13 & 0 \\
& International & 0 & 7 & 16 \\
& National & 4 & 8 & 12 \\
& Regional & 8 & 19 & 13
\end{tabular}

categories $(n=106)$, both divided into private, civil and public sectors and in relation to the level of governance

\section{Maintenance}

\section{Indicators}

The LTSER platforms' most frequent mean number of full-time workers (indicator C8) was three to five persons, but almost the same proportion of the respondents said one to two persons $(n=29$, Fig. 5a).

Research (ecological 29\%, social $11 \%$ ) accounted for the largest funding expenditure for the platforms (indicator C9). Other expenses included data collection $(26 \%)$, co-ordination (16\%), travels in the field $(12 \%)$ and stakeholder engagement $(7 \%, \mathrm{n}=29$, Fig. 5b).

Regarding funding sources (indicator C10) almost $90 \%$ of the LTSER platforms relied on national grants, and that about $50 \%$ of the platforms were supported by EU grants as well as from regional sources $(n=29$, Fig. 5c).

The "duration of secured funding" (indicator C11) was not long-term. Most commonly funding was secured for 1-2 years (37\%) in advance. About 30\% of the LTSER platforms reported funding for the next $3-5$ years $(n=29$, Fig. $5 d)$.

"Long-term survival" (indicator C12) was assessed by comparing data for 2010 with those for 2016 . Of the 30 platforms listed in 2010, only three had disappeared by 2016 (Fig. 6).

\section{Narratives}

The maintenance of LTSER platforms demonstrated a wide diversity of patterns with three groups 
Fig. 6 Number of LTSER platforms in 2010 according to Mirtl et al. (2013, p. 434; excluding Jordan) and those listed at the end of 2016 according to the DEIMSSDR data base. The indicator "delivering the digital platform boundary" and responsiveness to four surveys sent out to all 67 self-appointed platforms in the DEIMS-SDR data base, as well as how many platforms that responded to them, are also shown

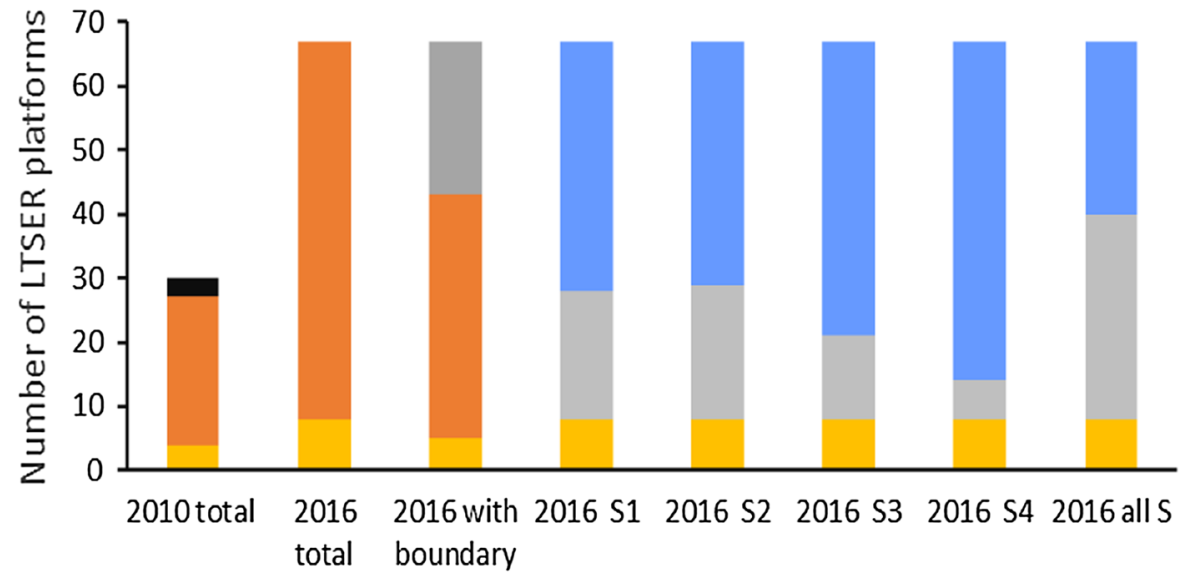

Responded to all surveys

- Not in DEIMS 2016

Responded $<=1 \mathrm{~S}$

\author{
nisted in DEIMS \\ no spatial data \\ nid not respond to survey/s
}

respectively (Table 5). According to "Site classification" a total of 32 entries were classified as approved LTSER platforms (M. Mirtl in e-mail 2017-06-06). DEIMS-SDR reported 43 entries with LTSER platform polygons. Next, we compared the results from DEIMS-SDR including LTSER entry polygons with those that answered Surveys $1-4$, as well as with those entries classified as existing/approved versus candidate/not approved (Table 5). In total, 43 LTSER platforms responded to at least one of the four surveys. Of the 43 LTSER platforms that had provided spatial boundaries in DEIMS-SDR only five responded to all four surveys. While 14-29 LTSER platforms replied to Surveys 1-4 individually, 21 replied to both Surveys 1 and 2, 10 to Surveys $1-3$, and only 8 to all 4 surveys (see Table 5). Of the latter five were "approved" as LTSER platforms and three were not. Except for LTSER platforms that had delivered polygons and were approved had a significantly higher response rate, there was no statistically significant difference between the response rates of "approved" and "not approved" platform entries for the other surveys (Table 5).

To assess LTSER platforms as a communicating network of place-based research, based on the guidelines for the LTSER network, we used as a proxy the frequency of occurrence of LTSER platforms that responded to four different surveys and how fast they responded to them in relation to the requested 14 day limit (Indicator D14). As shown in Fig. 7 in the first most simple survey all but 1 of the 28 platforms that responded met this requirement. With increasing survey complexity response times became longer.

The opportunity for analyzing socio-economic data collected at the level of public administrative units (Indicator D15) was estimated by comparing our estimates of how large (i.e. $10,000 \mathrm{~km}^{2}$ ) a sufficiently sized LTSER platform ought to mirror the size of a sufficiently large areas that reflects both ecological and social system analyses comprehensively on one hand, and the size of administrative units at different levels of governance on the other. Of the 43 LTSER platforms for which a polygon could be attributed, a total of 18 were $1000-10,000 \mathrm{~km}^{2}$ in size and 8 met the requirement of $10,000 \mathrm{~km}^{2}$ (Fig. 8). The NUTS classification (Nomenclature of Territorial Units for Statistics) is a hierarchical system for dividing the territory of the EU. The purpose is the collection, development and harmonization of European regional statistics enabling socio-economic analyses of the regions at three levels, viz. NUTS 1: major socioeconomic regions, NUTS 2: basic regions for the application of regional policies, and NUTS 3: small regions for specific diagnoses. Additionally, to meet the demand for statistics at local level, Eurostat has set up a system of local administrative units (LAUs) compatible with NUTS. At the local level, two levels of LAU have been defined. The upper LAU level 
Table 5 Overview of the extent to which 67 LTSER platforms listed in DEIMS-SDR in December 2016 responded to four surveys sent out (Surveys-1-4)

\begin{tabular}{|c|c|c|c|c|c|}
\hline & \multicolumn{2}{|c|}{$\begin{array}{l}\text { Total (proportion of all } 67 \\
\text { listed in DEIMS-SDR in this } \\
\text { column) }\end{array}$} & \multirow{2}{*}{$\begin{array}{l}\text { "Approved" } \\
\text { (relative proportion } \\
\text { of row total in \%) } \\
\mathrm{n}\end{array}$} & \multirow{2}{*}{$\begin{array}{l}\text { "Not approved"a } \\
\text { (relative proportion } \\
\text { of row total in \%) } \\
\text { n }\end{array}$} & \multirow[t]{2}{*}{$\begin{array}{l}\text { Statistical significance } \\
\text { based on one-tailed } \\
\text { binomial test }\end{array}$} \\
\hline & $\mathrm{n}$ & $\%$ & & & \\
\hline Listed as derived above & 67 & 100 & $32(48)$ & $35(52)$ & $\begin{array}{l}\mathrm{p}=0.40 \\
\mathrm{z}=-0.24\end{array}$ \\
\hline With polygon & 43 & 62 & $28(65)$ & $15(35)$ & $\begin{array}{l}\mathrm{p}=0.03 \\
\mathrm{z}=1.83\end{array}$ \\
\hline Responded to Survey-1 & 28 & 41 & $17(61)$ & $11(39)$ & $\begin{array}{l}\mathrm{p}=0.17 \\
\mathrm{z}=0.94\end{array}$ \\
\hline Responded to Survey-2 & 29 & 42 & $13(45)$ & $16(55)$ & $\begin{array}{l}\mathrm{p}=0.35 \\
\mathrm{z}=-0.37\end{array}$ \\
\hline Responded to Survey-3 & 21 & 30 & $13(62)$ & $8(38)$ & $\begin{array}{l}\mathrm{p}=0.19 \\
\mathrm{z}=0.87\end{array}$ \\
\hline Responded to Survey-4 & 14 & 20 & $7(50)$ & $7(50)$ & $\begin{array}{l}\mathrm{p}=0.5 \\
\mathrm{z}=0\end{array}$ \\
\hline Responded to one survey & 43 & 62 & $23(53)$ & $20(47)$ & $\begin{array}{l}\mathrm{p}=0.38 \\
\mathrm{z}=0.30\end{array}$ \\
\hline Responded to Surveys- 1 and -2 & 21 & 30 & $12(57)$ & $9(43)$ & $\begin{array}{l}\mathrm{p}=0.33 \\
\mathrm{z}=0.43\end{array}$ \\
\hline Responded to Surveys-1-3 & 10 & 15 & $6(60)$ & $4(40)$ & $\begin{array}{l}\mathrm{p}=0.37 \\
\mathrm{z}=0.31\end{array}$ \\
\hline Responded to Surveys-1-4 & 8 & 12 & $5(63)$ & $3(37)$ & $\begin{array}{l}\mathrm{p}=0.36 \\
\mathrm{z}=0.35\end{array}$ \\
\hline
\end{tabular}

The gross numbers is divided into those LTSER platforms that were approved by the national LTER network hubs and those that were not approved

${ }^{\mathrm{a}}$ For definition, see Mirtl et al. (2008)

(LAU level 1, formerly NUTS level 4) is defined for most of the countries, and the lower LAU level (LAU level 2, formerly NUTS level 5) consists of municipalities or equivalent units in the 28 EU Member States.

To estimate the number of NUTS and LAU units in an area of $10,000 \mathrm{~km}^{2}$, the area of each country and the number of units in each of NUTS 1-3 and LAU 1-2 were used to calculate the number of NUTS and LAU units in different sized areas (Fig. 9). While LAU 2 regions are found in all the countries in the EU LAU 1 is used only in some countries. The results indicate that there are several large LTSER platforms that have the potential to be used to compare results from analyses of green infrastructure functionality on the one hand and socio-economic data capturing human well-being in a sample of local administrative regions, for example in gradients between rural and urban areas. ${ }^{1}$ Additionally, more than half of the 43 LTSER platforms that had provided GIS polygon data were large enough to capture data from at least a few administrative units, which thereafter can be employed as a base for comparative studies of multiple LTSER platforms.

Data about the inclusion of LTSER platforms listed in DEIMS-SDR into the national research infrastructure roadmap European Strategy Forum on Research Infrastructures (ESFRI; Herbert Haubold pers. comm.) show that $52 \%$ of the countries hosting a total of 67 LTSER platform initiatives were supported by their respective countries to joining ESFRI. For those

\footnotetext{
$\overline{1}$ http://www.oecd.org/gov/regional-policy/functionalurbanareas bycountry.htm.
} 


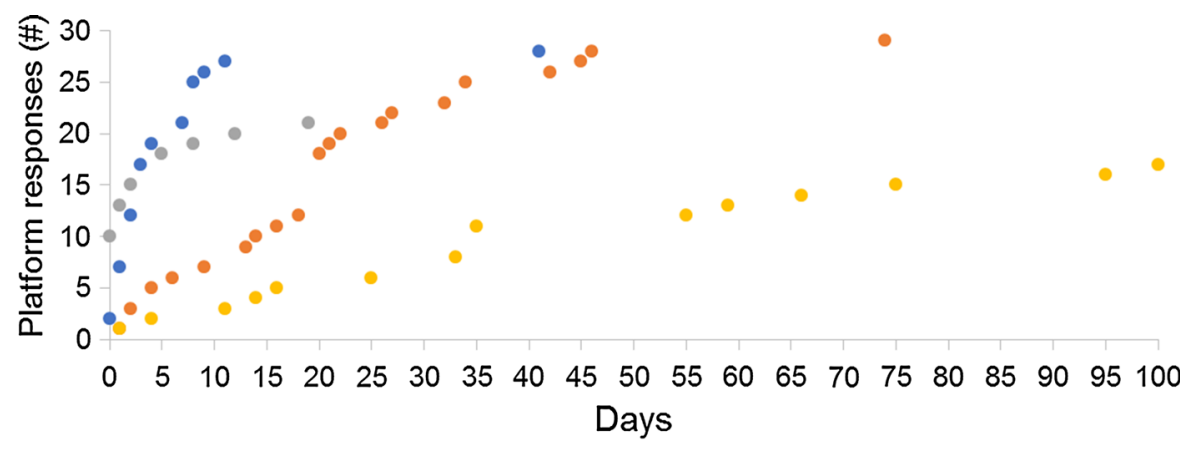

\section{- Survey 1 - Survey 2 - Survey 3 - Survey 4}

Fig. 7 LTSER platforms' response time in days after distribution of four surveys with increasing complexity. Survey-1 was an e-mail asking for contact persons; Surveys-2 (shorter) and -4 (longer) using text web-survey software, and Survey-3 was a

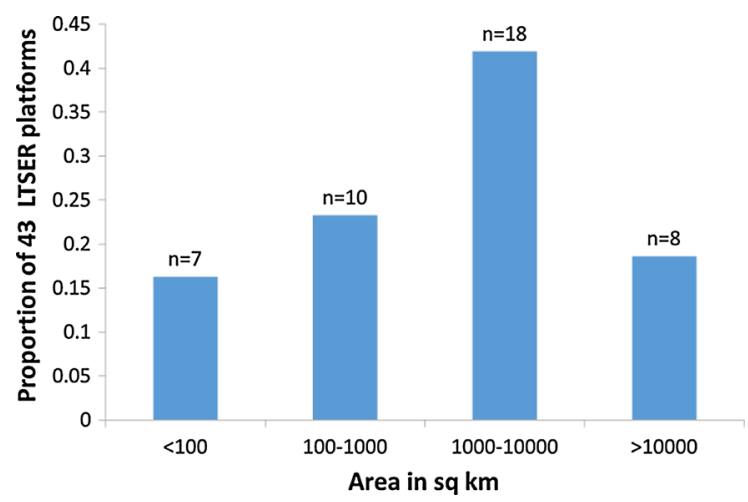

Fig. 8 Distribution of the 43 LTSER platforms that provided a GIS polygon divided into four size classes with the two largest offering opportunities for regional meta-analyses of socioecological data at municipal or parish levels (local administrative units 1 and 2)

43 platforms with boundaries in DEIMS-SDR a total of $50 \%$ were supported by their respective host countries.

\section{Narratives}

Finally, networking with other LTSER platforms, but also networking or being part of a range of other landscape approach concepts, was widespread. This included Model Forest, EU LEADER, UNESCO Biosphere Reserve, Zone Atelier, World Heritage Site, and Ramsar, as well as a wide range of professional and researcher networks. map web-survey software where LTSER platforms checked and if necessary edited the polygon showing the platform boundary. For details about sample sizes see Table 5. According to Mirtl et al. (2008) requested response time is 10 days

\section{Discussion}

Comparisons with the normative model for LTSER platforms

LTSER emerged in response to the recognition of increased effects of human activities on sustainability at local to global levels (Singh et al. 2013; Mirtl et al. 2018). These challenges can often be considered as wicked (Duckett et al. 2016), which calls for integrative modes of knowledge production and learning (Angelstam et al. 2013b; Holzer et al. 2018). With the aim of monitoring and diagnosing, as well as treating socio-ecological systems by contributing to problemsolving, the LTSER platform concept aims at being a type of place-based infrastructure that supports collaborative knowledge production and learning by academic and non-academic participants (Haberl et al. 2006; Singh et al. 2013). As a network, the ambition is to develop context-specific solutions by drawing upon multiple LTSER platforms representing biophysical, anthropogenic and intangible properties of landscapes as social-ecological systems (e.g., Matthews and Selman 2006; Metzger et al. 2010). We used mixed quantitative and qualitative methods to collect data representing the four LTSER platform criteria siting, construction, maintenance and networking and a total of 16 indicators as well as 18 narratives; Table 6 provides an overview of the compliance with the normative model.

The siting of LTSER platforms affects the opportunity to design both macroecological research 
Fig. 9 Mean number of units in NUTS and LAU regions that can be fitted into an area of $10,000 \mathrm{~km}^{2}$. Note that Norway and Israel are not EU Members

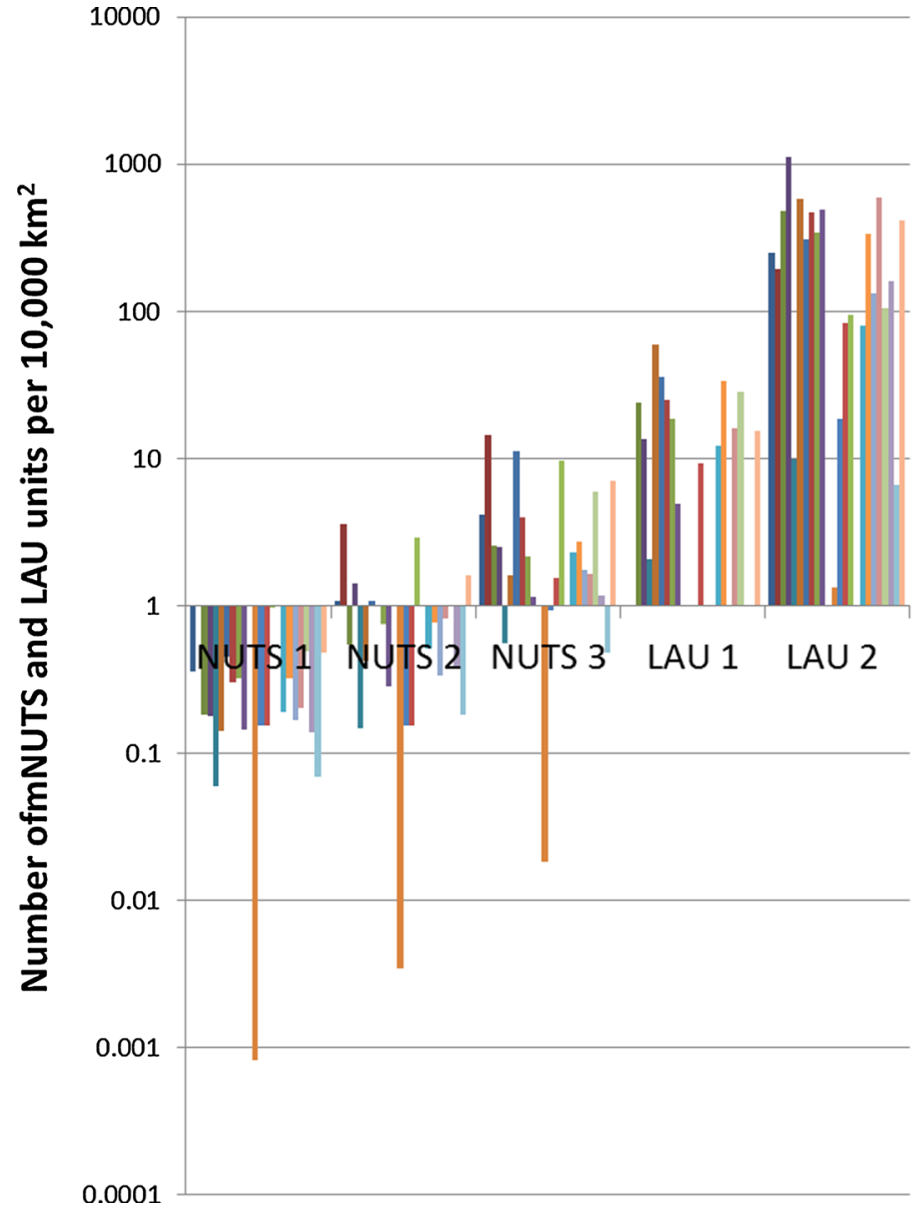

austria (AT)

a Belgium (BE)

n Bulgaria (BG)

- Czech Republic (CZ)

a Finland (FI)

arance (FR)

- Germany (DE)

- Greece (EL)

- Hungary (HU)

- Ireland (IE)

- Israel

- Italy (IT)

- Latvia (LV)

- Lithuania (LT)

Netherlands (NL)

norway

- Poland (PL)

- Portugal (PT)

nomania (RO)

- Slovakia (SK)

Slovenia (SI)

๓ Spain (ES)

Sweden (SE)

United Kingdom (UK)
(Brown 1995), natural experiments (Diamond 1986) and comparative studies of government, governance and politics (e.g., Hague and Harrop 2007), methods that rely on LTSER platforms as case studies, i.e. as a sample of places and spaces. From this point-of-view, the European LTSER platforms represented the socioecological diversity within the EU well (Metzger et al. 2010). However, parts of important socio-economic, landscape history and governance gradients that exist on the entire European continent by including also post-Soviet countries, are missing from this network. The absence of large intact forest landscapes as reference areas for ecological integrity, and of regions with clearly top-down governance with low levels of democracy, are two examples (see Fig. 4b, c and Angelstam et al. 2013a). This is highly relevant both when designing macroecological studies and comparisons of social systems. For example, dose-response studies about landscape patterns such as the effect of habitat amount and configuration on biodiversity (e.g., Roberge et al. 2008; Angelstam et al. 2018b), and processes such as the effects of large herbivores on trees (Angelstam et al. 2017b), demonstrate that the design in terms of the range of variation in independent variables affects the results. Similarly, comparative studies of different governance arrangements illustrate that different societal trajectories require solutions that are regionally adapted to both stakeholder engagement patterns and spatial planning legacies (e.g., Elbakidze et al. 2010, 2013). This also applies within local landscapes, such as where large differences in land ownership and tenure systems can be found. Finally, the net result of sustainability of landscapes of socio-economic pressures on species, habitats and ecosystem processes, and responses in terms of planning and management, need to be assessed (e.g., Haberl et al. 2009). 
Table 6 Opportunities for improvement of LTSER platforms' performance as place-based research infrastructure

\begin{tabular}{|c|c|c|}
\hline Criterion & Indicators & Opportunities for improvement \\
\hline \multirow[t]{3}{*}{ Siting (A) } & 1. Ecoregional representation & - \\
\hline & 2. Representation of anthropogenic change & $\begin{array}{l}\text { Include reference areas representing ecological integrity and } \\
\text { resilience }\end{array}$ \\
\hline & $\begin{array}{l}\text { 3. Representation of intangible } \\
\text { interpretations }\end{array}$ & Include wider gradients of governance and political cultures \\
\hline \multirow{4}{*}{$\begin{array}{l}\text { Construction } \\
\text { (B) }\end{array}$} & 4. Human versus natural science research & Strengthen the role of humanities and social sciences \\
\hline & 5. LTER sites in LTSER platforms & Encourage macroecological approaches \\
\hline & 6. Stakeholder structure & - \\
\hline & 7. Land ownership structure & - \\
\hline \multirow{5}{*}{$\begin{array}{l}\text { Maintenance } \\
\text { (C) }\end{array}$} & 8. Number of full time workers & - \\
\hline & 9. How funding is spent on main functions & $\begin{array}{l}\text { Increase proportion funding spent for humanities and social } \\
\text { sciences }\end{array}$ \\
\hline & 10. Funding sources & Funding at EU-level need to support also local LTSER platforms \\
\hline & 11. Duration of secured future funding & Need to encourage longer term funding \\
\hline & 12. Past survival & - \\
\hline \multirow[t]{4}{*}{ Network (D) } & 13. Reaction frequency & Develop incentives for cross-platform collaboration \\
\hline & 14. Response time & Develop incentives for cross-platform collaboration \\
\hline & 15. Opportunity for regional meta-analyses & Compare macroecological and socio-economic data \\
\hline & 16. National support & Increased support from north and east European countries \\
\hline
\end{tabular}

At the network level a critically important dimension of a LTSER research infrastructure is that it covers wide gradients in all dimensions of landscape. First, this involves capturing the full gradient of ecosystem states, for example from forests intensively managed for wood and biomass to remnants of nearnatural forest landscapes as benchmarks with ecological integrity for landscape restoration, or grasslands of different kinds (e.g., Manton and Angelstam 2018). Second, the network needs to cover a wide range of social systems, such as from bottom-up democratic governance to top-down authoritarian (e.g., Elbakidze et al. 2010). To achieve this, the LTSER network needs to establish platforms outside the EU as well as collaborate with other concepts.

The post-Soviet zapovednik system for strictly protected areas, including monitoring data and phenological letters of nature (Weiner 1999; Shtilmark 2003), is a grand infrastructure to build on. However, problems with funding of place-based research, and all other kinds research, began during last years of the Soviet era. For example, in Ukraine, the situation deteriorated significantly in the years after independence in 1991 because (i) most equipment bought in former Soviet times was either outdated or nonfunctional, (ii) the state allocated funds for wages of research staff only, and (iii) research infrastructure was gradually destroyed as there was no money for maintenance. Ukraine has thus practically backwatered in environmental studies for the past 25 years and the process of active brain-drain is ongoing. Bureaucratized and non-transparent procedures including corruption are also issues. The maintenance of the existing research stations and sites in Ukraine are possible mostly due to financial support through EU and other international projects and interested partners (e.g., Kovalova et al. 2010; Medinets 2014; Medinets et al. 2016). Slovakia was in similar situation before entrance to EU in 2004. Although EU funds helped to improve situation impacts of the previous regime can be felt, in an initial phase of democracy which blocks development in comparison to the western part of EU. Thus, the most efficient way to develop a network in such countries with limited financial opportunities would be to implement EU projects that are dedicated to support the establishment of a LTSER platforms network in both EU and former post-Soviet countries. 
Concerning the construction of LTSER platforms, experiences illustrate that the addition of the "socio"component to already established long-term ecological monitoring/research sites is not straightforward. This is reflected both by a dominance of ecological research according to our survey work, and a dominance of ecological research in peer-review publications (Dick et al. 2018). Nevertheless, the same study demonstrated that the trend over time is positive for social science contributions from LTSER platforms. The development of sustainability science (e.g., Komiyama and Takeuchi 2006; Kates 2011) is a response to the need for holistic knowledge production and learning on the ground towards sustainable landscapes. Moving from research restricted to natural science or human science research towards transdisciplinary knowledge production through collaborating researchers, practitioners and citizens means a radical change in the way knowledge production is carried out and how infrastructure for this is built (Holzer et al. 2018). Despite addressing multiple spatial scales from land cover patches to regions, engaging stakeholders at different levels of governance, and problemoriented research being highly topical (Durham et al. 2014), there often is epistemological and methodical frictions when engaging in transdisciplinary research (e.g., Furman and Peltola 2013; Mirtl et al. 2013).

So far, the LTSER platform concept has been viewed through an ecosystem and natural science lens. This is clearly illustrated by Haberl's et al. (2006) comparison of key features of ecosystem research and the LTSER philosophy, which leaves out the social science perspective (see left and center part of Table 7). To balance this, the LTSER platform concept also needs to incorporate the perspectives of social sciences and the humanities (see right part of Table 7 added by us). To achieve this, mutual respect from both cultures of human and natural science research (sensu "two cultures" of Snow 1959), respectively, is required. An analysis of 14 case studies of transdisciplinary research efforts (Angelstam et al. 2013c) showed the barriers between the two cultures can be bridged by (1) reducing disciplinary formal and informal controls by securing successive funding, (2) integrating social and natural science research and stakeholder engagement projects to fulfil transdisciplinary research agendas, (3) better and more widely engaging stakeholders along the entire research and knowledge production processes, and
(4) team building based on collaboration, self-reflection and experienced leadership. Developing a research agenda overarching multiple LTSER platforms, and bridging research-management-policy gaps would be in important contribution. The 18 LTSER platform narratives in this study provide ample inspiration.

The number of researchers involved in maintaining LTSER platforms was most commonly 1-2 (38\%) followed by $3-5$ persons (30\%; Fig. 5). Research work accounted for three quarters of platform expenditures, which suggests that added cost for transdisciplinarity by ensuring stakeholder engagement is considerable. This often means that transdisciplinary research needs to secure and integrate funding for three kinds of projects, viz. natural science, human science and stakeholder engagement. Overall the project portfolios were mainly funded by national level grants, but also through EU funding. The funding schemes ranged from having some basic funding for co-ordination and stakeholder engagement from regional or national organization, to only soft project funding, the objectives of which steer the kinds of research that can be carried out. Regarding the longevity of LTSER platforms, the duration of project funding was predominantly for 1-2 years, and about $30 \%$ of the platforms had secured funding for 3-5 years. This was dependent on the success of securing grants. Being a young landscape approach concept, the LTSER platforms in this study covered only the period 2010-2016, at the end of which 27 of the initial 30 LTSER platforms in 2010 remained listed 2016 in the DEIMS-SDR database.

Networking activities can be assessed using several types of proxy data. Focusing on the four surveys, the response rates ranged from 40 to $20 \%$, the decrease of which was in parallel to the increasing complexity of surveys. Whether or not LTSER platforms listed in DEIMS-SDR were formally approved at the national level did not affect the response rates. Another proxy for networking is the fact that several LTSER platforms were also affiliated to other landscape approach concepts, such as UNESCO Biosphere Reserve, Ramsar and World Heritage Site, Model Forest (IMFN 2008) as well as many professional and research networks.

The qualitative approach based on 18 narratives about the siting, construction, maintenance and networking of LTSER platforms in different development 
Table 7 Comparison of key features of long-term ecosystem research (LTER) and LTSER philosophy (modified after Haberl et al. 2006), and social system research according to
Castree and Braun (2001) and Keiny (2002) on the epistemology of social research and Burns (2007) on methods, approaches and products

\begin{tabular}{|c|c|c|c|}
\hline System studied & Ecological system (LTER) & Socio-ecological system (LTSER) & Social system (the "S") \\
\hline $\begin{array}{l}\text { Subject of } \\
\text { research }\end{array}$ & Material physical world & $\begin{array}{l}\text { The material physical and human } \\
\text { social world, how society } \\
\text { functions, and social relationships } \\
\text { including politics, economy etc. }\end{array}$ & $\begin{array}{l}\text { Study of society and the manner in } \\
\text { which people behave and } \\
\text { influence the world around us }\end{array}$ \\
\hline $\begin{array}{l}\text { Humans are dealt } \\
\text { with as... }\end{array}$ & $\begin{array}{l}\text {...human populations, treated like } \\
\text { populations of other species, } \\
\text { causing disturbances in } \\
\text { ecosystems }\end{array}$ & $\begin{array}{l}\text {..human societies/cultures } \\
\text { engaged in an interactive process } \\
\text { with their natural environment }\end{array}$ & $\begin{array}{l}\text {...creators of discourse and social } \\
\text { structure, according to their } \\
\text { values and culture, addressed for } \\
\text { individuals, groups and } \\
\text { community. The structure and } \\
\text { functioning of the social system } \\
\text { determine interactions with the } \\
\text { environment }\end{array}$ \\
\hline $\begin{array}{l}\text { Methods/ } \\
\text { approaches }\end{array}$ & $\begin{array}{l}\text { Natural sciences approach: } \\
\text { observation-analysis- } \\
\text { explanation. Intervention occurs } \\
\text { only in controlled experiments }\end{array}$ & $\begin{array}{l}\text { Inter- and transdisciplinary } \\
\text { approach: gets involved and is } \\
\text { aware that the research may } \\
\text { change the systems under } \\
\text { investigation }\end{array}$ & $\begin{array}{l}\text { Quantitative approach (studies the } \\
\text { size or extent of particular issues } \\
\text { or trends in society) or qualitative } \\
\text { research (explores how } \\
\text { individuals think, feel or behave } \\
\text { in particular situations), or both. } \\
\text { In some cases, the intervention is } \\
\text { for a change }\end{array}$ \\
\hline Products & $\begin{array}{l}\text { Expertise, measurement data, } \\
\text { models, understanding of system } \\
\text { dynamics }\end{array}$ & $\begin{array}{l}\text { As LTER plus socioeconomic and } \\
\text { statistical data. Actively uses } \\
\text { research results as a basis for } \\
\text { participation in decision making }\end{array}$ & $\begin{array}{l}\text { Evidence about how societies } \\
\text { (social structures and processes) } \\
\text { changes (quantitative or } \\
\text { qualitative) predict human } \\
\text { behaviors and influence policies } \\
\text { and practices }\end{array}$ \\
\hline $\begin{array}{l}\text { Basic } \\
\text { epistemological } \\
\text { assumptions }\end{array}$ & $\begin{array}{l}\text { Natural-scientific values: aims at } \\
\text { objectivity and reproducibility, } \\
\text { may sometimes have the illusion } \\
\text { to be independent of social values } \\
\text { and norms }\end{array}$ & $\begin{array}{l}\text { Self-reflexivity: is aware that } \\
\text { research is a social process } \\
\text { inextricably entangled in } \\
\text { historically [(time) and } \\
\text { geographically (space)] } \\
\text { contingent social values and } \\
\text { norms }\end{array}$ & $\begin{array}{l}\text { People are experts of the system in } \\
\text { which they live, so research } \\
\text { cooperation with them is } \\
\text { essential. Research is social } \\
\text { process that can be both objective } \\
\text { (if positive) or subjective (in } \\
\text { more radical social studies) }\end{array}$ \\
\hline
\end{tabular}

stages and landscape contexts corroborates the quantitative analysis, but also illustrates their heterogeneity. The narratives also demonstrate the long period from the appearance of a transdisciplinary idea to its realization (e.g., Angelstam and Törnblom 2004; Axelsson et al. 2013; Bretagnolle et al. 2018). While on the one hand this can be an obstacle for establishing a place-based distributed network of landscape approach initiatives as research infrastructure within ESFRI, a positive pragmatic approach is to encourage collaboration in different constellations of LTSER platforms based on their characteristics. Applying a multiple case study approach benefits from the heterogeneity of LTSER platforms (e.g., Angelstam and Elbakidze 2017; Angelstam et al. 2018a). Finally, the size of LTSER platform areas matter at the network level. Addressing interactions between macroecological patterns and processes on the one hand and governance, political cultures and socioeconomic factors on the other requires platform areas that are sufficiently large to contain multiple territorial units that can provide such data. The diversity of individual LTSER platforms is thus of concern; this is illustrated by that the 18 case studies of LTSER initiatives ranged from 90 to $78,000 \mathrm{~km}^{2}$, and from 1 to 91 administrative units. 
Landscape approach as a social innovation

Aimed at supporting use of evidence-based knowledge in governance, planning and management towards sustainable development and sustainability LTSER platform is an example of the wide spectrum of initiatives labeled landscape approach. Landscape approach entails a collaborative effort of researchers, stakeholders, practitioners and policy makers towards bottom-up projects and actions to promote a sustainable development process and sustainability in their own place and region (Axelsson et al. 2011; Sayer et al. 2013, 2015). At the end of the 1990s, many authors started calling this process social innovation (Moulaert et al. 2005). Creative actions, social participation, collaboration among different levels of decision making and different sectors of society are all common features of social innovation. There are three ecological registers that must be articulated to promote sustainability: environmental ecology, social ecology and mental ecology (Guattari 1989). The landscape approach as social innovation considers these "three ecologies" as constitutive parts of the landscape: nature and environment, social relations and structures as well as subjectivity (Council of Europe 2000). The necessary conditions for developing place-based transdisciplinary research representing different social-ecological contexts include: (1) existence of long-term data about ecological and social systems, "compass" sensu Lee (1993), (2) sufficient time for developing collaborative capacity, "gyroscope" sensu Lee (1993), and (3) sufficient coordination (Angelstam and Elbakidze 2017; Angelstam et al. 2018a).

Human behavior and decision making are based on being part of a community, building bonds with places and by stakeholders sharing meaning about landscape, nature and social realities. Currently, the term social innovation is conceptualized in different ways and used across different fields of knowledge, such as creativity, business, management, economy, psychology and rural development (Mulgan 2006; Marcy and Mumford 2007; Neumeier 2012, 2017; Maurer and Silva 2014; Bock 2016). In general, “... social innovation starts from the presumption that people are competent interpreters of their own lives and competent solvers of their own problems..." (Mulgan 2006, p. 150). Rather than waiting for institutional or governmental solutions through top-down intervention and policy, local communities can promote collaborative ways to address their needs and desires as well as to transfer their outcomes into public policies (OECD 2017). This calls for revival of collective action (Primdahl et al. 2018), which can be sought both through analyses of past local collective systems for landscape stewardship, and where they remain in terms of for example traditional village systems (Elbakidze and Angelstam 2007; Angelstam and Elbakidze 2017).

The main goal of social innovation from the perspective of landscape approach is to facilitate that a place-based, permanent and renewable change takes place toward a more equitable and sustainable society. Neumeier (2012, p. 55) defined social innovation as "changes in attitudes, behaviors or perceptions of a group of people joined in a network of aligned interests that in relation to the group's horizon of experience lead to new and improved ways of collaborative action within the group and beyond". It can thus help address important challenges for local communities and groups related to the three ecologies proposed by Guattari (1989). Social innovation, as a crucial intangible interpretation of landscape (Grodzynsky 2005), can support building personal and collective empowerment, and moving from passive position to agency (Bruner 1996).

Sharing of quality-assured harmonized practices among LTSER platforms and other landscape approach concepts as social innovations can improve practices for multi-level learning through evaluation at the place-based landscape level. At the network level, understanding of landscapes as socio-ecological systems can be scaled up to help improve governance, planning and management models towards implementation of policy such as the UN Sustainable Development Goals (2015), functional green infrastructures (European Commission 2013), and rural development (OECD 2017). The European Union's Horizon 2020 funding for establishment of a research infrastructure based on Long-Term Social-Ecological Research (LTSER) platforms (Mirtl et al. 2013) is an attempt to create a research infrastructure across the European Union (eLTER; see http://www.lter-europe.net/elter). One option for improved cohesion among place-based initiatives aimed at transdisciplinary research is the ESFRI, which supports policy-making on research infrastructures and encourages a coherent, strategy-led approach across Europe. ESFRI (2016) declares that the future prosperity of landscapes and regions in an 
increasingly competitive, globalized and knowledgebased economy relies on the potential of scientific and technological innovation. This requires high quality educational and research institutions, a strong focus on skills and high quality facilities for research that provide evidence-based knowledge. To facilitate multilateral initiatives leading to the better use and development of research infrastructures, ESFRI publishes roadmaps for the construction and development of the next generation of Pan-European research infrastructures across a broad range of scientific fields (ESFRI 2016). By putting eLTER on the ESFRI Roadmap in 2018, ESFRI has underpinned the importance of LTER sites and LTSER platforms as a part of the European Research Infrastructure in terms of integrated ecosystem, critical zone and socio-ecological research. This opens up significant new avenues for scientific and operational development, deepening collaborations and bringing in new tools for funding. This is urgently required to address the interconnected wicked challenges of economic development, ecological integrity, and social justice that are essential components of human well-being through a stronger territorial basis (e.g., Duckett et al. 2016).

Additionally, several networks focus on landscape restoration sites (IUCN and WRI 2014) and on sustainable landscape management in the tropics (Denier et al. 2015). Other global level concepts and processes aiming at of landscape approach are UNESCO's Biosphere Reserves, the International Model Forest Network (www.imfn.net) and the Global Landscapes Forum (www.landscapes.org). There is thus potential for integration among different landscape approach concepts and initiatives as a research infrastructure that can support implementation of more sustainable models of practice and management that are effective on the ground. This would enhance the use of Pan-European gradients in biophysical, anthropogenic and intangible interpretations of landscapes for knowledge production and learning towards sustainable social-ecological systems. However, the high-level praise of landscape approach as a tool (e.g., World Forestry Congress 2009; Sayer et al. 2013, 2015) need to be matched by effective bridging of barriers in terms of competition between organizations and concepts that focus only on their own version of what a landscape approach means. We therefore encourage wide use of our systematic approach to learning through evaluation.
Acknowledgements We acknowledge funding from EU Horizon 2020 for the Research Infrastructure Project eLTER, FORMAS (Project Number 2017:1342) and the Lithuanian Science Council (Project Number P-MIP-17-107). We thank numerous colleagues for inspiring comments to the survey questions and parts of the text, and Jennifer Holzer and referees for commenting the emerging manuscript.

Open Access This article is distributed under the terms of the Creative Commons Attribution 4.0 International License (http:// creativecommons.org/licenses/by/4.0/), which permits unrestricted use, distribution, and reproduction in any medium, provided you give appropriate credit to the original author(s) and the source, provide a link to the Creative Commons license, and indicate if changes were made.

\section{References}

Angelstam P, Andersson K, Annerstedt M, Axelsson R, Elbakidze M, Garrido P, Grahn O, Jönsson I, Pedersen S, Schlyter P, Skärbäck E, Smith M, Stjernquist I (2013a) Solving problems in social-ecological systems: definition, practice and barriers of transdisciplinary research. Ambio 42(2):254-265

Angelstam P, Barnes G, Elbakidze M, Marsh A, Marais C, Mills A, Polonsky S, Richardson DM, Rivers N, Shackleton R, Stafford W (2017a) Collaborative learning to unlock investments for functional ecological infrastructure: bridging barriers in social-ecological systems in South Africa. Ecosyst Serv 27:291-304

Angelstam P, Elbakidze M (2017) Forest landscape stewardship for functional green infrastructures in Europe's West and East: diagnosing and treating social-ecological systems. In: Bieling C, Plieninger T (eds) The science and practice of landscape stewardship. Cambridge University Press, Cambridge, pp 124-144

Angelstam P, Elbakidze M, Axelsson R, Dixelius M, Törnblom J (2013b) Knowledge production and learning for sustainable landscapes: seven steps using social-ecological systems as laboratories. Ambio 42(2):116-128

Angelstam P, Elbakidze M, Lawrence A, Manton M, Melecis V, Pereira A (2018a) Barriers and bridges for landscape stewardship and knowledge production to sustain functional green infrastructures. In: Pereira A, Peterson U, Pastur G, Iverson L, Plieninger $\mathrm{T}$ (eds) Sustaining ecosystem services in forest landscapes. Springer, Dordrecht, pp 127-167

Angelstam P, Grodzynskyi M, Andersson K, Axelsson R, Elbakidze M, Khoroshev A, Kruhlov I, Naumov V (2013c) Measurement, collaborative learning and research for sustainable use of ecosystem services: landscape concepts and Europe as laboratory. Ambio 42(2):129-145

Angelstam P, Manton M, Pedersen S, Elbakidze M (2017b) Disrupted trophic interactions affect recruitment of boreal deciduous and coniferous trees in northern Europe. Ecol Appl 27(4):1108-1123

Angelstam P, Naumov V, Elbakidze M, Manton M, Priednieks J, Rendenieks Z (2018b) Wood production and biodiversity 
conservation are rival forestry objectives in Europe's Baltic Sea Region. Ecosphere 9(3), Article e02119

Angelstam P, Roberge J-M, Lõhmus A, Bergmanis M, Brazaitis G, Dönz-Breuss M, Edenius L, Kosinski Z, Kurlavicius P, Lārmanis V, Lūkins M, Mikusinski G, Račinskis E, Strazds M, Tryjanowski P (2004) Habitat modelling as a tool for landscape-scale conservation-a review of parameters for focal forest birds. Ecol Bull 51:427-453

Angelstam P, Törnblom J (2004) Maintaining forest biodiversity in actual landscapes-European gradients in history and governance systems as a "landscape lab". In: Marchetti M (ed) Monitoring and indicators of forest biodiversity in Europe-from ideas to operationality. Symposium no. 51. European Forest Institute. p 299-313

Anon (2009) A Long-Term Biodiversity, Ecosystem and Awareness Research Network LTER Europe GUIDELINE on best practices, version 3. http://www.lter-europe.net/ document-archive/central/Best $\% 20$ practice $\% 20$ guideline $\%$ 20v3-June1.pdf

Axelsson R, Angelstam P, Elbakidze M, Stryamets N, Johansson K-E (2011) Sustainable development and sustainability: landscape approach as a practical interpretation of principles and implementation concepts. J Landsc Ecol 4(3):5-30

Axelsson R, Angelstam P, Myhrman L, Sädbom S, Ivarsson M, Elbakidze M, Andersson K, Cupa P, Diry C, Doyon F, Drotz MK, Hjorth A, Hermansson JO, Kullberg T, Lickers FH, McTaggart J, Olsson A, Pautov Yu, Svensson L, Törnblom J (2013) Evaluation of multi-level social learning for sustainable landscapes: perspective of a development initiative in Bergslagen, Sweden. Ambio 42(2):241-253

Baker S (2006) Sustainable development. Routledge, London

Bezák P, Mederly P, Izakovičová Z, Špulerová J, Schleyer C (2017) Divergence and conflicts in landscape planning across spatial scales in Slovakia: an opportunity for an ecosystem services-based approach? Int J Biodivers Sci Ecosyst Serv Manag 13(2):119-135

Bieling C, Plieninger T (eds) (2017) The science and practice of landscape stewardship. Cambridge University Press, Cambridge

Bock B (2016) Rural marginalisation and the role of social innovation: a turn towards nexogenous development and rural reconnection. Sociol Rural 56(4):552-573

Bretagnolle V, Berthet E, Gross N, Gauffre B, Plumejeaud C, Houte S, Badenhausser I, Monceaua K, Allier F, Monestiez P, Gaba S (2018) Towards sustainable and multifunctional agriculture in farmland landscapes: lessons from the integrative approach of a French LTSER platform. Sci Total Environ 627:822-834

Brown JH (1995) Macroecology. University of Chicago Press, Chicago

Bruner J (1996) The culture of education. Harvard University Press, Cambridge

Burns D (2007) Systemic action research: a strategy for whole system change. Policy Press, Bristol

Castree N, Braun B (2001) Social nature theory, practice, and politics. Wiley-Blackwell, London

Charmaz K (2014) Constructing grounded theory. Sage, Thousand Oaks
Council of Europe (2000) European Landscape Convention. European Treaty Series No. 176

Dawson L, Elbakidze M, Angelstam P, Gordon J (2017) Governance and management dynamics of landscape restoration at multiple scales: learning from successful environmental managers in Sweden. J Environ Manag 197:24-40

De Groot RS, Alkemade R, Braat L, Hein L, Willemen L (2010) Challenges in integrating the concept of ecosystem services and values in landscape planning, management and decision making. Ecol Complex 7(3):260-272

Deng X, Li Z, Gibson J (2016) A review on trade-off analysis of ecosystem services for sustainable land-use management. J Geogr Sci 26(7):953-968

Denier L, Scherr S, Shames S, Chatterton P, Hovani L, Stam N (2015) The little sustainable landscapes book. Global Canopy Programme, Oxford

Diamond J (1986) Overwiew: laboratory experiments field experiments and natural experiments. In: Diamond JM, Case TJ (eds) Community ecology. Harper and Row, New York, pp 3-22

Dick J, Orenstein DE, Holzer JM, Wohner C, Achard AL, Andrews C, Avriel-Avni N, Beja P, Blond N, Cabello J, Chen C, Díaz-Delgado R, Giannakis GV, Gingrich S, Izakovicova Z, Krauze K, Lamouroux N, Leca S, Melecis V, Miklós K, Mimikou M, Niedrist G, Piscart C, Postolache C, Psomas A, Santos-Reis M, Tappeiner U, Vanderbilt K, Van Ryckegem G (2018) What is socioecological research delivering? A literature survey across 25 international LTSER platforms. Sci Total Environ 622:1225-1240

Duckett D, Feliciano D, Martin-Ortega J, Munoz-Rojas J (2016) Tackling wicked environmental problems: the discourse and its influence on practice in Scotland. Landsc Urban Plan 154:44-56

Durham E, Baker H, Smith M, Moore E, Morgan V (2014) The BiodivERsA stakeholder engagement handbook. BiodivERsA, Paris

Eisenhardt KM (1989) Building theories from case study research. Acad Manag Rev 14:532-550

Elbakidze M, Angelstam P (2007) Implementing sustainable forest management in Ukraine's Carpathian Mountains: the role of traditional village systems. For Ecol Manag 249:28-38

Elbakidze M, Angelstam P, Sandström C, Axelsson R (2010) Multi-stakeholder collaboration in Russian and Swedish Model Forest initiatives: adaptive governance towards sustainable forest management? Ecol Soc 15(2):14

Elbakidze M, Angelstam P, Yamelynets T, Dawson L, Gebrehiwot M, Stryamets N, Johansson KE, Garrido P, Naumov V, Manton M (2017) A bottom-up approach to map land covers as potential green infrastructure hubs for human well-being in rural settings: a case study from Sweden. Landsc Urban Plan 168:72-83

Elbakidze M, Hahn T, Mauerhofer V, Angelstam P, Axelsson R (2013) Legal framework for biosphere reserves as learning sites for sustainable development: a comparative analysis of Ukraine and Sweden. Ambio 42(2):174-187

European Commission (2013) Green infrastructure (GI)-enhancing Europe's natural capital. COM 249. European Commission, Brussels 
European Strategy Forum on Research Infrastructures, ESFRI (2016) Strategy report on research infrastructures. Science and Technology Facilities Council. http://ec.europa.eu/ research/infrastructures

Flyvbjerg B (2006) Five misunderstandings about case-study research. Qual Inq 12:219-245

Flyvbjerg B (2011) Case study. In: Denzin NK, Lincoln Y (eds) The Sage handbook of qualitative research, 4th edn. Sage, Thousand Oaks, pp 301-316

Furman E, Peltola T (2013) Developing socio-ecological research in Finland: challenges and progress towards a thriving LTSER network. In: Singh SJ, Haberl H, Chertow M, Mirtl M, Schmid M (eds) Long term socio-ecological research. Springer, Dordrecht, pp 443-459

Garrido P, Elbakidze M, Angelstam P, Plieninger T, Pulido F, Moreno G (2017) Stakeholder perspectives of wood pasture ecosystem services: a case study from Iberian dehesas. Land Use Policy 60:324-333

Gingrich S, Schmid M, Dirnböck T, Dullinger I, Garstenauer R, Gaube V, Haberl H, Kainz M, Kreiner D, Mayer R, Mirtl M, Sass O, Schauppenlehner T, Stocker-Kiss A, Wildenberg M (2016) Long-term socio-ecological research in practice: lessons from inter- and transdisciplinary research in the Austrian Eisenwurzen. Sustainability 8(8):743

Grodzynsky MD (2005) Piznannia Landshaftu: Misce i Prostir [Understanding landscape: place and space]. Two volumes. Kiev University Publishing House, Kiev (in Ukrainian)

Grove JM, Pickett STA, Whitmer A, Cadenasso ML (2013) Building and urban LTSER: the case of the Baltimore ecosystem study and the D.C./B.C., ULTRA-Ex project. In: Singh JS, Haberl H, Schmid M, Mirtl M, Chertow M (eds) Long term socio-ecological research studies in society nature interactions across temporal and spatial scales. Springer, Dordrecht, pp 369-408

Guattari F (1989) Les trois écologies. Galilée, Paris

Haberl H, Winiwarter V, Andersson K, Ayres RU, Boone C, Castillo A, Cunfer G, Fischer-Kowalski M, Freudenburg WR, Furman E, Kaufmann R, Krausmann F, Langthaler E, Lotze-Campen H, Mirtl M, Redman CL, Reenberg A, Wardell A, Warr B, Zechmeister H (2006) From LTER to LTSER: conceptualizing the socioeconomic dimension of long-term socioecological research. Ecol Soc 11(2). https://www.jstor.org/stable/26266031

Haberl H, Gaube V, Díaz-Delgado R, Krauze K, Neuner A, Peterseil J, Plutzar C, Singh SJ, Vadineanu A (2009) Towards an integrated model of socioeconomic biodiversity drivers, pressures and impacts. A feasibility study based on three European long-term socio-ecological research platforms. Ecol Econ 68:1797-1812

Hague R, Harrop M (2007) Comparative government and politics. Palgrave Macmillan, New York

Holzer JM, Carmon N, Orenstein DE (2018) A methodology for evaluating transdisciplinary research on coupled socioecological systems. Ecol Indic 85:808-819

IMFN (2008) Model Forest development guide. International Model Forest Network Secretariat, Ottawa

IUCN and WRI (2014) A guide to the Restoration Opportunities Assessment Methodology (ROAM). IUCN, Gland

Kates RW (2011) What kind of science is sustainability science? Proc Natl Acad Sci USA 108:19449-19450
Keiny S (2002) Ecological thinking: a new approach to educational change. University Press of America, Lanham

Komiyama H, Takeuchi K (2006) Sustainability science: building a new discipline. Sustain Sci 1:1-6

Kovalova NV, Medinets SV, Konareva OP, Medinets VI (2010) Long-term changes of bacterioplankton and chlorophyll a as indicators of changes of northwestern part of the Black Sea ecosystem during the last 30 years. Environ Prot Ecol 11(1):191-198

Lähteenmäki-Smith K (ed) (2007) Learning through evaluation: the Nordic experience. Nordregio Report 2007:3

Lambeck RJ (1997) Focal species: a multi-species umbrella for nature conservation. Conserv Biol 11(4):849-856

Lee KN (1993) Compass and gyroscope: integrating science and politics for the environment. Island Press, Covelo

Lindelöw D (2018) Running to stand still-the role of travel time in transport planning. SWECO, Gothenburg

Locatelli B, Lavorel S, Sloan S, Tappeiner U, Geneletti D (2017) Characteristic trajectories of ecosystem services in mountains. Front Ecol Environ 15(3):150-159

Luederitz C, Schäpke N, Wiek A, Lang DJ, Bergmann M, Bos JJ, Burch S, Davies A, Evans J, König A, Farrelly MA, Forrest N, Frantzeskaki N, Gibson RB, Kay B, Loorbach D, McCormick K, Parodi O, Rauschmayer F, Schneidewind U, Stauffacher M, Stelzer F, Trencher G, Venjakob J, Vergragt PJ, von Wehrden H, Westley FR (2017) Learning through evaluation. A tentative evaluative scheme for sustainability transition experiments. J Clean Prod 169:61-76. https:// urldefense.proofpoint.com/v2/urlu=https3A_doi.org_10. 1016_j.jclepro.2016.09.005\&d=DwIFAw\&c=vh6FgFndue jNhPPD0fl_yRaSfZy8CWbWnIf4XJhSqx8\&r=r2aSgYn6P HMQXXmeBiKsnvfFG9T9U5fmdQ67xEVmgo0\&m=1IBk 1uimUdS8gzgYJtMSFe5hYGJ749S36qv5zUYdi68\&s= 9rjZolQd_188Xjlelf5DQnzAx1c8J77641QCkIT-a2o\&e=

Manton M, Angelstam P (2018) Defining benchmarks for restoration of green infrastructure: a case study combining the historical range of variability of habitat and species' requirements. Sustainability 10:326

Marcy RT, Mumford MD (2007) Social innovations: enhancing creative performance through causal analysis. Creat Res J 19:123-140

Matthews R, Selman P (2006) Landscape as a focus for integrating human and environmental processes. J Agric Econ 57(2):199-212

Maurer AM, Silva TN (2014) Analytical dimensions for identifying social innovations: evidence from collective enterprises. Braz Bus Rev 11(6):127-150

Medinets S (2014) The Black Sea nitrogen budget revision in accordance with recent atmospheric deposition study. Turk J Fish Aquat Sci 14:981-992

Medinets S, Gasche R, Skiba U, Medinets V, Butterbach-Bahl K (2016) The impact of management and climate on soil nitric oxide fluxes from arable land in the Southern Ukraine. Atmos Environ 137:113-126

Metzger MJ, Bunce RGH, Van Eupen M, Mirtl M (2010) An assessment of long term ecosystem research activities across European socio-ecological gradients. J Environ Manag 91(6):1357-1365

Millennium Ecosystem Assessment (2005) Ecosystems and human well-being: synthesis. Island Press, Washington,DC 
Mirtl M, Borer ET, Djukic I, Forsius M, Haubold H, Hugo W, Jourdan J, Lindenmayer D, McDowell WH, Muraoka H, Orenstein DE, Pauw JC, Peterseil J, Shibata H, Wohner C, Yu X, Haase P (2018) Genesis, goals and achievements of long-term ecological research at the global scale: a critical review of ILTER and future directions. Sci Total Environ 626:1439-1462

Mirtl M, Frenzel M, Furman E, Ohl C, Krauze K, Grünbühel C (2008) LTER-EUROPE: criteria and recommendations. Version 5.2, 2008-05-27.http://www.lter-europe.net/ document-archive/central/I3034v02-LTER-EuropeCriteria.pdf

Mirtl M, Orenstein DE, Wildenberg M, Peterseil J, Frenzel M (2013) Development of LTSER platforms in LTER-Europe: challenges and experiences in implementing placebased long-term socio-ecological research in selected regions. In: Singh SJ, Haberl H, Chertow M, Mirtl M, Schmid M (eds) Long term socio-ecological research. Springer, Dordrecht, pp 409-442

Mollenhauer H, Kasner M, Haase P, Peterseil J, Wohner C, Frenzel M, Mirtl M, Schima R, Bumberger J, Zacharias S (2018) Long-term environmental monitoring infrastructures in Europe: observations, measurements, scales, and socio-ecological representativeness. Sci Total Environ 624:968-978

Moulaert F, Martinelli F, Swyngedouw E, Gonzales S (2005) Towards alternative model(s) of local innovation. Urban Stud 42(11):1969-1990

Mulgan $G$ (2006) The process of social innovation. Innov Technol Gov Glob 1(2):145-162

Muñoz-Rojas J, Nijnik M, González-Puente M, Cortines-García F (2015) Synergies and conflicts in the use of policy and planning instruments for implementing forest and woodland corridors and networks; a case study in NE Scotland. For Policy Econ 57:47-64

Naumov V, Manton M, Elbakidze M, Rendenieks Z, Priedniek J, Uglyanets S, Yamelynets T, Zhivotov A, Angelstam P (2018) How to reconcile wood production and biodiversity conservation? The Pan-European boreal forest history gradient as an "experiment". J Environ Manag 218:1-13

Neumeier S (2012) Why do social innovations in rural development matter and should they be considered more seriously in rural development research? Proposal for a stronger focus on social innovations in rural development research. Sociol Rural 52(1):48-69

Neumeier S (2017) Social innovation in rural development: identifying the key factors of success. Geogr J 183(1):34-46

Norton BG (2005) Sustainability: a philosophy of adaptive ecosystem management. University of Chicago Press, Chicago

Noss RF (1990) Indicators for monitoring biodiversity: a hierarchical approach. Conserv Biol 4(4):355-364

OECD (2017) New Rural Policy: linking up for growth. OECD Publications, Paris. http://www.fao.org/family-farming/ detail/en/c/522521/. Accessed 31 March 2018

Pedroli B, Pinto-Correia T, Cornish P (2006) Landscapewhat's in it? Trends in European landscape science and priority themes for concerted research. Landscape Ecol 21(3):421-430
Potapov PA, Yaroshenko A, Turubanova S, Dubinin M, Laestadius L, Thies C, Aksenov D, Egorov A, Yesipova Y, Glushkov M, Karpachevskiy M, Kostikova A, Manisha A, Tsybikova E, Zhuravleva I (2008) Mapping the world's intact forest landscapes by remote sensing. Ecol Soc 13(2):51

Potschin M, Haines-Young R (2013) Landscapes, sustainability and the place-based analysis of ecosystem services. Landscape Ecol 28(6):1053-1065

Primdahl J, Kristensen L, Arler F, Angelstam P, Aagaard Christensen A, Elbakidze M (2018) Rural landscape governance and expertise - on landscape agents and democracy. In: Egoz S, Jorgensen K, Ruggeri D (eds) Defining landscape democracy: a path to spatial justice. Edward Elgar Publishing, Cheltenham

Roberge J-M, Angelstam P, Villard M-A (2008) Specialised woodpeckers and naturalness in hemiboreal forestsderiving quantitative targets for conservation planning. Biol Conserv 141:997-1012

Sabogal C, Besacier C, McGuire D (2015) Forest and landscape restoration: concepts, approaches and challenges for implementation. Unasylva 66(245):3-10

Sayer J, Margules C, Boedhihartono AK, Dale A, Sunderland T, Supriatna J, Saryanthi R (2015) Landscape approaches; what are the pre-conditions for success? Sustain Sci 10(2):345-355

Sayer J, Sunderland T, Ghazoul J, Pfund JL, Sheil D, Meijaard E, Venter M, Boedhihartono AK, Day M, Garcia C, van Oosten C (2013) Ten principles for a landscape approach to reconciling agriculture, conservation, and other competing land uses. Proc Natl Acad Sci USA 110(21):8349-8356

Schuck A, Van Brusselen J, Päivinen R, Häme T, Kennedy P, Folving S (2002) Compilation of a calibrated European forest map derived from NOAA-AVHRR data. European Forest Institute. EFI Internal Report 13, plus Annexes

Shtilmark F (2003) History of the Russian zapovedniks. Russian Nature Press, Exeter

Singh SJ, Haberl H, Chertow M, Mirtl M, Schmid M (2013) Introduction. In: Singh SJ, Haberl H, Chertow M, Mirtl M, Schmid M (eds) Long term socio-ecological research: studies in society-nature interactions across spatial and temporal scales. Springer, Dordrecht, pp 1-26

Snow CP (1959) The two cultures. Cambridge University Press, New York

Stake RE (2006) Multiple case study analysis. The Guilford Press, New York

Termorshuizen JW, Opdam P (2009) Landscape services as a bridge between landscape ecology and sustainable development. Landscape Ecol 24(8):1037-1052

United Nations, UN (2015) Resolution adopted by the General Assembly on 25 September 2015. 70/1. Transforming our world: the 2030 Agenda for Sustainable Development. United Nations

van Bueren LEM, Blom EM (1997) Hierarchical framework for the formulation of sustainable forest management standards. Tropenbos Foundation, Wageningen

Van Cuong C, Dart P, Hockings M (2017) Biosphere reserves: attributes for success. J Environ Manag 188:9-17

Weiner DR (1999) A little corner of freedom: Russian nature protection from Stalin to Gorbachëv. University of California Press, Berkeley 